This document was prepared in conjunction with work accomplished under Contract No. DE-AC09-96SR18500 with the U. S. Department of Energy.

\title{
DISCLAIMER
}

This report was prepared as an account of work sponsored by an agency of the United States Government. Neither the United States Government nor any agency thereof, nor any of their employees, makes any warranty, express or implied, or assumes any legal liability or responsibility for the accuracy, completeness, or usefulness of any information, apparatus, product or process disclosed, or represents that its use would not infringe privately owned rights. Reference herein to any specific commercial product, process or service by trade name, trademark, manufacturer, or otherwise does not necessarily constitute or imply its endorsement, recommendation, or favoring by the United States Government or any agency thereof. The views and opinions of authors expressed herein do not necessarily state or reflect those of the United States Government or any agency thereof.

This report has been reproduced directly from the best available copy.

Available for sale to the public, in paper, from: U.S. Department of Commerce, National Technical Information Service, 5285 Port Royal Road, Springfield, VA 22161, phone: (800) 553-6847, fax: (703) 605-6900

email: orders@ntis.fedworld.gov

online ordering: http://www.ntis.gov/help/index.asp

Available electronically at http://www.osti.gov/bridge

Available for a processing fee to U.S. Department of Energy and its contractors, in paper, from: U.S. Department of Energy, Office of Scientific and Technical Information, P.O. Box 62, Oak Ridge, TN 37831-0062,

phone: (865)576-8401,

fax: (865)576-5728

email: $\underline{\text { reports@ adonis.osti.gov }}$ 
Key Words:

Salt Disposition

MST

Retention:

Permanent

\section{MONOSODIUM TITANATE MULTI-STRIKE TESTING}

Mark J. Barnes

Fernando F. Fondeur

David T. Hobbs

Samuel D. Fink

APRIL 29, 2004

Westinghouse Savannah River Company

Savannah River Site

Aiken, SC 29808

Prepared for the U.S. Department of Energy Under

Contract Number DE-AC09-96SR18500 
This page was intentionally left blank 


\section{TABLE OF CONTENTS}

LIST OF FIGURES .................................................................................................................... iv

LIST OF TABLES .........................................................................................................................

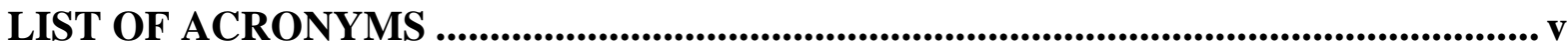

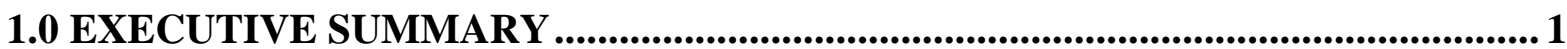

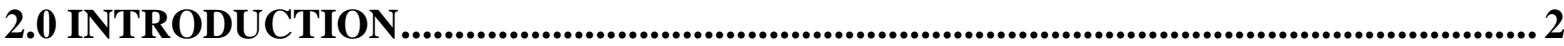

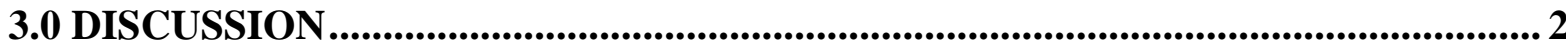

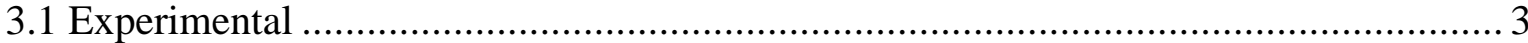

3.1.1 Simulant Adsorption Testing .................................................................... 3

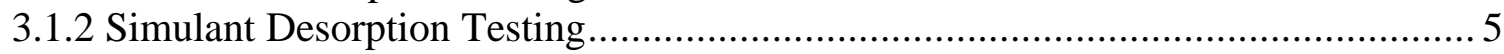

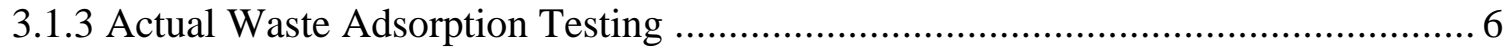

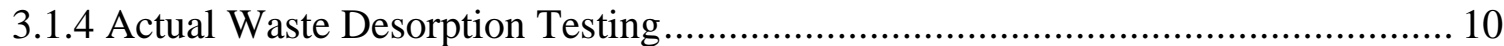

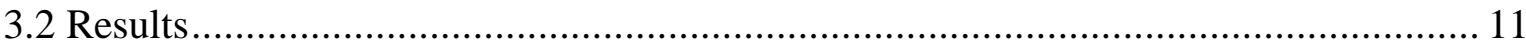

3.2.1 Simulant Adsorption Testing ..................................................................... 11

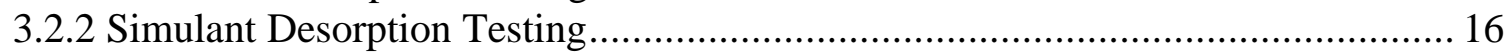

3.2.3 Actual Waste Adsorption Testing ………..................................................... 17

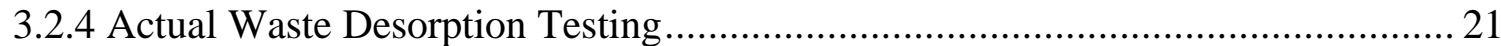

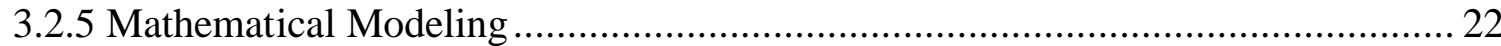

3.2.5.1 Prediction of Sorption Performance ………………................................. 22

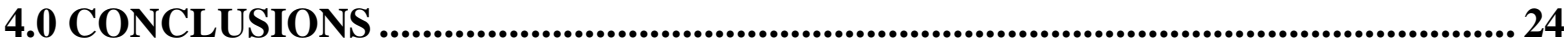

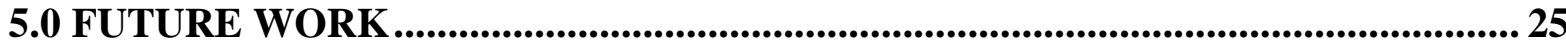

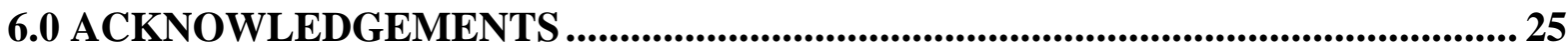

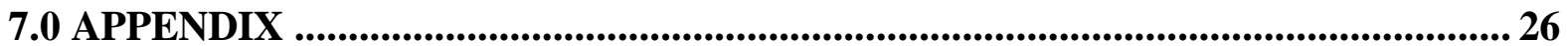

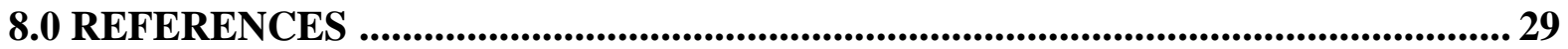




\section{LIST OF FIGURES}

Figure 3-1 Equilibration of Stock Simulant Salt Solution ................................................. 4

Figure 3-2 Residual MST (Post-Centrifuging) Solids prior to Desorption Testing .................. 6

Figure 3-3 Equilibration of Tank 39H Waste Feed Solution ............................................... 7

Figure 3-4 Actual Waste Adsorption Test Equipment .................................................... 9

Figure 3-5 Residual MST (Post-Centrifuging) Solids from Test H prior to Desorption Testing

Figure 3-6 Desorption Test Vessel with Residual MST Solids and Diluted Supernate .......... 11

Figure 3-7 Simulant Adsorption Test Plutonium Results .................................................... 12

Figure 3-8 Simulant Adsorption Test Plutonium Results - Expanded View ........................ 12

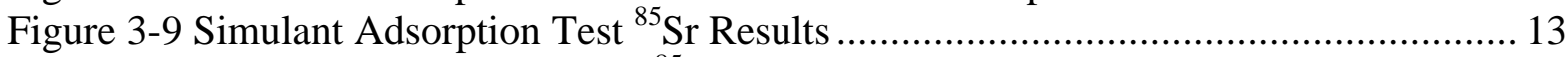

Figure 3-10 Simulant Adsorption Test ${ }^{85}$ Sr Results - Expanded View................................. 13

Figure 3-11 Simulant Adsorption Test ${ }^{237} \mathrm{~Np}$ Results..................................................... 14

Figure 3-12 Simulant Adsorption Test ${ }^{237}$ Np Results - Expanded View .............................. 14

Figure 3-13 Simulant Adsorption Test U Results .......................................................... 15

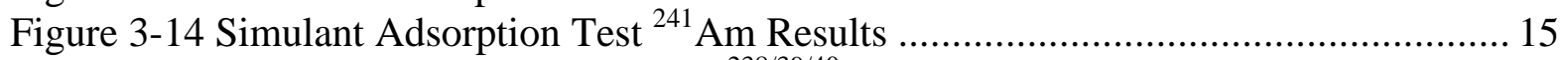

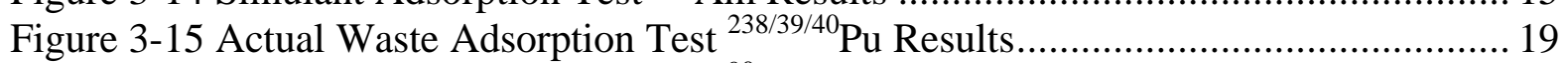

Figure 3-16 Actual Waste Adsorption Test ${ }^{90}$ Sr Results .................................................. 19

Figure 3-17 Actual Waste Adsorption Test U Results ...................................................... 20

Figure 3-18 The X-Value of the Intercept of the Operating Line with the Predicting Isotherm

Gives the Final Concentration for a Given Batch Contact ........................................... 22

Figure 3-19 The Effect of Multiple MST Strikes and Filtration on the Final Actinide

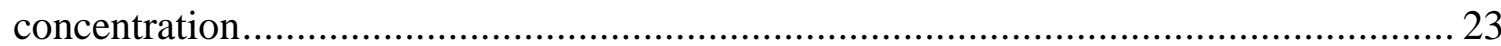

\section{LIST OF TABLES}

Table 3-1 Simulant Salt Solution Composition................................................................. 3

Table 3-2 Soluble Strontium and Actinide Concentrations in the Simulant Salt Solution....... 4

Table 3-3 Simulant Adsorption Testing Protocols ............................................................ 5

Table 3-4 Equilibration of Soluble Strontium and Actinides in Tank 39H Waste Solution..... 8

Table 3-5 Actual Waste Adsorption Test Protocols ............................................................. 9

Table 3-6 Simulant Adsorption Test Decontamination Factors............................................ 16

Table 3-7 Simulant Desorption Test Characteristics ........................................................... 17

Table 3-8 Simulant Desorption Test Data - Concentration Units of nCi/g ........................... 17

Table 3-9 Soluble Actinides Composition of 5.6 M Na Tank 39H Waste ............................. 18

Table 3-10 Actual Waste Adsorption Test Decontamination Factors ................................... 20

Table 3-11 Actual Waste Desorption Test Characteristics ................................................... 21

Table 3-12 Actual Waste Desorption Test Data - Concentration Units of nCi $/ \mathrm{g}$................... 21

Table 3-13 Measured Versus Predicted Solution Concentrations for Simulant Adsorption

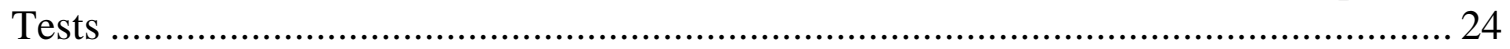

Table 3-14 Measured Versus Predicted Solution Concentrations for Actual Waste Adsorption

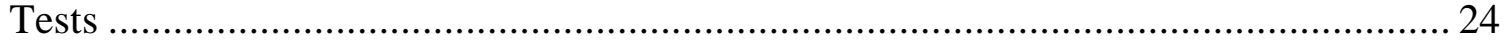

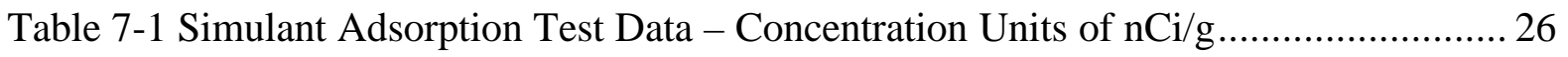

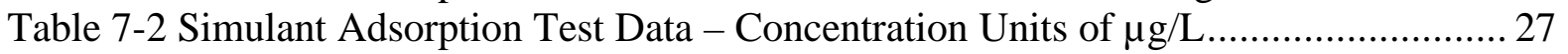

Table 7-3 Actual Waste Adsorption Test Data - Concentration Units of nCi/g.................... 28

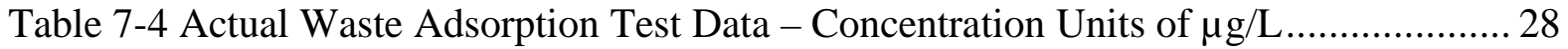




\section{LIST OF ACRONYMS}

$\begin{array}{ll}\text { AA } & \text { Atomic Absorption } \\ \text { ADS } & \text { Analytical Development Section } \\ \text { Am } & \text { Americium } \\ \text { AMP } & \text { Ammonium Molybdophosphate } \\ \text { Cs } & \text { Cesium } \\ \text { DF } & \text { Decontamination Factor } \\ \text { DOE } & \text { Department of Energy } \\ \text { HLW } & \text { High-Level-Waste } \\ \text { ICP-MS } & \text { Inductively Coupled Plasma-Mass Spectrometry } \\ \text { MST } & \text { Monosodium Titanate } \\ \text { Np } & \text { Neptunium } \\ \text { PE } & \text { Polyethylene } \\ \text { PES } & \text { Polyethylsulfone } \\ \text { Pu } & \text { Plutonium } \\ \text { PuTTA } & \text { Plutonium Triphenyltrifluoroacetone Scintillation Analysis } \\ \text { PVDF } & \text { Polyvinylidenedifluoride } \\ \text { Sr } & \text { Strontium } \\ \text { SRTC } & \text { Savannah River Technology Center } \\ \text { SWPF } & \text { Salt Waste Processing Facility } \\ \text { TT\&QAP } & \text { Task Technical and Quality Assurance Plan } \\ \text { U } & \text { Uranium } \\ \text { WAC } & \text { Waste Acceptance Criteria } \\ \text { WCS } & \text { Waste Characterization System } \\ \text { WPTS } & \text { Waste Processing Technology Section } \\ & \end{array}$


WSRC-TR-2004-00145, REV. 0

\subsection{EXECUTIVE SUMMARY}

Research over the past decade has studied the adsorption of plutonium and uranium onto monosodium titanate (MST) in alkaline solutions. Tests showed that MST would remove the targeted radionuclides from simulated alkaline waste. Testing also indicated that Pu removal kinetics and Np capacity of the MST material impacts the size of equipment and waste blending plans for the SWPF. Additionally, calculations suggested the baseline MST process (MST concentration of $0.4 \mathrm{~g} / \mathrm{L}$ ) may not achieve the desired decontamination in wastes containing elevated concentrations of $\mathrm{Pu}$ and $\mathrm{Np}$. In this task, the authors investigated the performance of non-baseline process parameters and their effectiveness for treating waste feed in the Salt Waste Processing Facility. The work addresses a DOE request in support of technical needs expressed, in part, by the Engineering, Procurement, and Construction Contractors for the Salt Waste Processing Facility. The work investigated the effect of increased MST addition (up to $1.2 \mathrm{~g} / \mathrm{L}$ ) and the benefit of extra filtration steps with multiple additions of MST to salt waste containing actinides and strontium. Both simulant and actual waste testing occurred. Actual waste tests utilized a Tank $39 \mathrm{H}$ composite waste solution. In addition, testing to determine desorption of actinides from residual MST occurred. The release of sorbed $\mathrm{Sr}$ and actinides from loaded MST during the washing stages in the Salt Waste Processing Facility is an unresolved process behavior. Desorption tests assessed this potential problem using loaded MST from the residue of the MST adsorption tests.

Programmatic conclusions drawn from this task follow.

- MST adsorption of Sr and actinides is minimally influenced by multi-strikes (alone) within the $24 \mathrm{~h}$ process cycle time.

- Use of intermediate filtration in conjunction with multiple MST strikes improves removal of $\mathrm{Pu}$ and $\mathrm{Sr}$. The low starting concentration of $\mathrm{Np}$ does not permit determining the influence of intermediate filtration on $\mathrm{Np}$ removal.

- The use of intermediate filtration in conjunction with multiple MST strikes is ineffective for increasing $\mathrm{U}$ and Am removal.

- The solubility of Am appears to fall well below the Waste Characterization System estimates.

- Desorption of $\mathrm{Sr}$ and $\mathrm{Pu}$ during $24 \mathrm{~h}$ of solids washing does not pose a threat to process limits.

Testing did not identify problematic areas requiring further investigation. However, testing showed that the use of AMP may have influenced the removal of ${ }^{241} \mathrm{Am}$, possibly caused by a filtration effect. (Note: AMP is a solid that can be added to prepare samples for analysis by adsorbing Cs, after which it is filtered out of solution). Slow precipitation of Am also occurred obscuring the data. The authors recommend follow-up testing to investigate this observation if AMP is to be continued for use in testing requiring ${ }^{241} \mathrm{Am}$ analysis. Analysis of non-radioactive $\mathrm{Sr}$ in the tests proved difficult due to the low concentration of nonradioactive $\mathrm{Sr}$ and its nearness to the method detection limit for ICP-MS. Efforts to utilize AMP to minimize dilution of actual waste for removal from the cell did not help for this analysis since instrument dilution still proved necessary due to the salt content.

Page 1 


\subsection{INTRODUCTION}

The Salt Waste Processing Facility (SWPF) at the Savannah River Site will use monosodium titanate (MST) for the removal of radioactive strontium ( $\mathrm{Sr}$ ), plutonium (Pu) and neptunium $(\mathrm{Np})$. MST has been investigated for more than a decade for use at SRS. Initial research ${ }^{1}$ studied the adsorption of Pu and uranium (U) onto MST in alkaline solutions. These tests showed that MST would remove the targeted radionuclides from simulated alkaline waste. Additional testing indicated that $\mathrm{Pu}$ removal kinetics impacts the size of equipment and waste blending plans for the SWPF. Additionally, calculations suggested the baseline MST process (MST concentration of $0.4 \mathrm{~g} / \mathrm{L}$ ) may not achieve the desired decontamination in wastes containing elevated concentrations of $\mathrm{Pu}^{2}$

The actinide removal process tests described in this document evaluate additional process parameters and their effectiveness for treating waste feed in the SWPF. The work addresses a DOE request in support of technical needs expressed, in part, by the Engineering, Procurement, and Construction Contractors for the Salt Waste Processing Facility. The work scope also incorporates the use of an analytical development tool aimed at improving sensitivity and accuracy of analyses (primarily for non-radioactive $\mathrm{Sr}$ ). The planned scope of work is documented in WSRC-RP-2003-00403, Rev. 1 (TT\&QAP). ${ }^{3}$ The work described in this document is only a portion of the entire work scope discussed in the referenced TT\&QAP.

The requested task and work scope documented within are as follows.

Monosodium Titanate Multi-strike Demonstration - Determine the effect of increased MST addition (up to $1.2 \mathrm{~g} / \mathrm{L}$ ) and benefit of extra filtration steps with multiple additions of MST to salt waste containing actinides and strontium. Both simulant and actual waste testing are required. In addition, testing to determine desorption of actinides from residual MST is also requested.

\subsection{DISCUSSION}

Testing for this task consisted of two groups: radioactive simulant and actual high-level-waste. Each group included two types of testing - $\mathrm{Sr}$ and actinides adsorption onto MST and desorption from residual or "loaded" MST. Adsorption testing provides a basis for evaluating various parameters currently being considered for use in the SWPF. Desorption testing provides the first prototypical data evaluating the potential problem of release or desorption of sorbed $\mathrm{Sr}$ and actinides from residual MST during washing later in the process. 


\subsection{EXPERIMENTAL}

\subsubsection{Simulant Adsorption Testing}

Monosodium titanate has been used for some time to remove actinides and strontium from salt waste solutions. ${ }^{1}$ The method of adsorption testing used in this task mimics the experimental methods used in prior tasks. The notable exception is that this task requires the testing of multiple MST concentrations, multiple MST strikes, and intermediate filtration to remove residual MST. Additionally, the filter size is changed to reflect intended plant use. Past studies used $0.45 \mu$ filters. The current testing used $0.1 \mu$ filters both for sampling and intermediate filtration.

Simulant adsorption testing represented the initial phase of testing for this task. Personnel prepared the standard simulant salt solution using a nitric acid prep to increase actinide solubility. The bulk salt composition of the simulant waste is described in Table 3-1. The simulant waste was spiked with target concentrations of ${ }^{238} \mathrm{U}_{\left(\mathrm{UO}_{2}{ }^{2+}\right)}$ at $10,000 \mu \mathrm{g} / \mathrm{L}$, ${ }^{239 / 240} \mathrm{Pu}\left(\mathrm{IV}\right.$ ) at $200 \mu \mathrm{g} / \mathrm{L},{ }^{237} \mathrm{~Np}(\mathrm{~V})$ at $500 \mu \mathrm{g} / \mathrm{L}$, and ${ }^{241} \mathrm{Am}$ (III) at $40 \mu \mathrm{g} / \mathrm{L}$. The target total strontium concentration was $600 \mu \mathrm{g} / \mathrm{L}$ (from tramp contaminant in other salts), spiked with ${ }^{85} \mathrm{Sr}$ tracer. The simulant solution equilibrated for 10 weeks prior to adsorption testing. Figure 3-1 provides a graph of the $\mathrm{Sr}$ and actinides during the equilibration period. Note the Am showed significant instability during the first 60 days of equilibration but stabilized prior to testing.

Table 3-1 Simulant Salt Solution Composition

\begin{tabular}{|c|c|}
\hline Component & Concentration (M) \\
\hline $\mathrm{NaNO}_{3}$ & 2.60 \\
\hline $\mathrm{NaOH}$ & 1.33 \\
\hline $\mathrm{Na}_{2} \mathrm{SO}_{4}$ & 0.521 \\
\hline $\mathrm{NaAl}(\mathrm{OH})_{4}$ & 0.429 \\
\hline $\mathrm{NaNO}_{2}$ & 0.134 \\
\hline $\mathrm{Na}_{2} \mathrm{CO}_{3}$ & 0.0260 \\
\hline $\mathrm{Total} \mathrm{Na}^{+}$ & 5.6 \\
\hline
\end{tabular}

Analysis was the same for the starting feed solution and subsequent adsorption tests. Sampling involved pulling approximately $4.0 \mathrm{~mL}$ of the test solution into a disposable $10-\mathrm{mL}$ syringe and filtering the sample mixture through a $0.1-\mu \mathrm{m}$ syringe filter disk (PVDF membrane) and into a sample bottle. Three milliliter portions of each filtered sample were pipetted into a second sample bottle containing $3 \mathrm{~mL}$ of $5 \mathrm{M}$ nitric acid. The diluted, acidified sample was manually shaken for approximately 15 seconds and then allowed to equilibrate for a minimum of 2 hours prior to submittal for analysis. Samples were analyzed for ${ }^{237} \mathrm{~Np},{ }^{238} \mathrm{U},{ }^{239 / 240} \mathrm{Pu},{ }^{241} \mathrm{Am}$, and ${ }^{85} \mathrm{Sr}$ concentrations by gamma spectroscopy, inductively coupled plasma-mass spectrometry (ICP-MS), Pu triphenyltrifluoroacetone scintillation analysis (PuTTA), and radiochemical methods. The soluble concentrations of ${ }^{85} \mathrm{Sr}$ and the actinides prior to testing are shown in Table 3-2. 


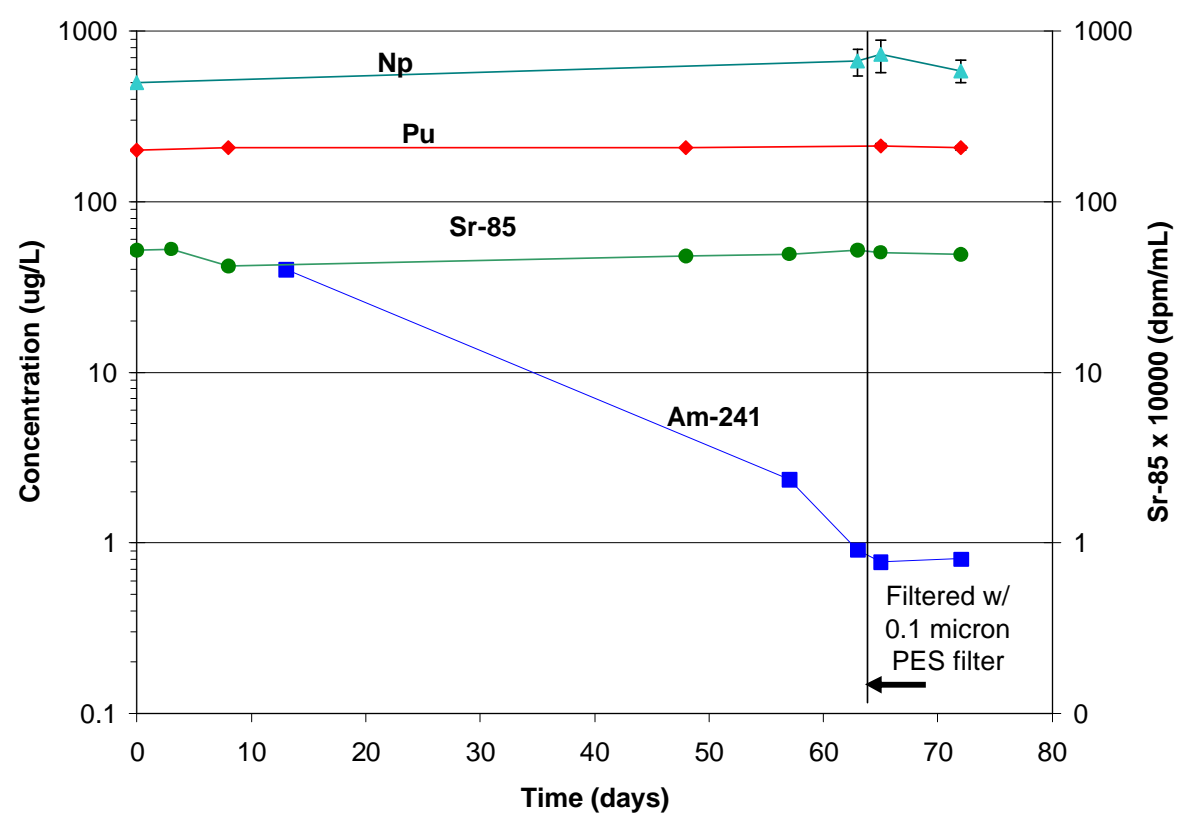

Figure 3-1 Equilibration of Stock Simulant Salt Solution

Table 3-2 Soluble Strontium and Actinide Concentrations in the Simulant Salt Solution

\begin{tabular}{|c|c|}
\hline Component & Concentration $(\mu \mathrm{g} / \mathrm{L})$ \\
\hline${ }^{238} \mathrm{U}$ & 11,650 \\
\hline${ }^{239 / 40} \mathrm{Pu}$ & 211 \\
\hline${ }^{237} \mathrm{~Np}$ & 562 \\
\hline${ }^{241} \mathrm{Am}$ & 0.75 \\
\hline Total $\mathrm{Sr}$ & 298 \\
\hline
\end{tabular}

The initial experiments with simulated waste used test protocols A through $\mathrm{F}$ shown in Table 3-3. All tests occurred in 250-mL polyethylene bottles fitted with a cap. Researchers prepared each test by placing $120 \mathrm{~mL}$ of the equilibrated simulant solution in the bottle. The desired amount of MST was added to each test by pipette at the appropriate time (i.e., postsampling and filtration for the multi-strike tests $\mathrm{D}$ and $\mathrm{E}$ and at $0 \mathrm{~h}$ for all other tests). The MST came from Optima Batch \#00-QAB-417. Sample containers were continuously shaken using an orbital shaking $(\sim 175 \mathrm{rpm})$ bath at a constant temperature of $25 \pm 3^{\circ} \mathrm{C}$. For those tests involving intermediate filtration, the residual (post-sampling) bulk test solutions were filtered through $0.1 \mu$ PES disposable cup filters. Sampling involved removing a test bottle from the shaker, manually shaking to produce a homogeneous mixture, pulling approximately $4.0 \mathrm{~mL}$ of the test mixture into a disposable 10- $\mathrm{mL}$ syringe, and filtering the sample mixture through a $0.1-\mu \mathrm{m}$ syringe filter disk (PVDF) and into a sample bottle. Three milliliter portions of each filtered sample were pipetted into a second sample bottle containing $3 \mathrm{~mL}$ of $5 \mathrm{M}$ nitric acid. The diluted, acidified sample was manually shaken for 
approximately 15 seconds and then allowed to equilibrate for a minimum of 2 hours prior to submittal for analysis. Samples were analyzed using the same methods as previously noted for the simulant stock solution.

Table 3-3 Simulant Adsorption Testing Protocols

\begin{tabular}{|c|l|}
\hline Test ID & \multicolumn{1}{|c|}{ Description } \\
\hline $\mathrm{A}$ & $\begin{array}{l}\text { Addition of } 0.4 \mathrm{~g} / \mathrm{L} \text { MST with sample analysis at } 0,6, \\
12,24,48, \text { and } 168 \mathrm{~h}\end{array}$ \\
\hline $\mathrm{B}$ & $\begin{array}{l}\text { Addition of } 0.8 \mathrm{~g} / \mathrm{L} \text { MST with sample analysis at } 0,6, \\
12,24,48, \text { and } 168 \mathrm{~h}\end{array}$ \\
\hline $\mathrm{C}$ & $\begin{array}{l}\text { Addition of } 1.2 \mathrm{~g} / \mathrm{L} \text { MST with sample analysis at } 0,6, \\
12,24,48, \text { and } 168 \mathrm{~h} \text {. Experiment conducted in } \\
\text { duplicate. }\end{array}$ \\
\hline $\mathrm{D}$ & $\begin{array}{l}\text { Add } 0.4 \mathrm{~g} / \mathrm{L} \text { MST (incrementally) at } 0,6, \text { and } 12 \mathrm{~h} \text { with } \\
\text { sample analysis at } 0,6,12,24,36,48, \text { and } 168 \mathrm{~h} \text { (prior } \\
\text { to incremental additions at } 6 \text { and } 12 \mathrm{~h} \text { ). }\end{array}$ \\
\hline $\mathrm{E}$ & $\begin{array}{l}\text { Add } 0.4 \mathrm{~g} / \mathrm{L} \text { MST (incrementally) at } 0,6, \text { and } 12 \mathrm{~h} \text { with } \\
\text { filtration }(0.1 \mu \mathrm{m} \text { ) prior to the second and third MST } \\
\text { strikes and with sample analysis at } 0,6,12,24,36,48, \\
\text { and } 168 \mathrm{~h} \text { (prior to filtrations and incremental additions } \\
\text { at } 6 \text { and } 12 \text { h). Experiment conducted in duplicate. }\end{array}$ \\
\hline F & $\begin{array}{l}\text { Control }- \text { no addition of MST with sample analysis at } 0, \\
6,12,24, \text { and } 168 \mathrm{~h} .\end{array}$ \\
\hline
\end{tabular}

\subsubsection{Simulant Desorption Testing}

A recently raised concern for the process is the potential for desorption or release of sorbed $\mathrm{Sr}$ and actinides from loaded (used) MST during the washing stages in the SWPF. Tests were performed to assess desorption from loaded MST using the residual solids from four of the previous MST adsorption tests: Tests A, B, C (actually Test C2 since duplicate C adsorption tests were conducted), and $\mathrm{D}$. No replicate desorption tests occurred. The tests were conducted by concentrating the residual MST solids using a centrifuge (see Figure 3-2). The solids concentration target before testing was set at $2 \mathrm{wt} \%$ MST. However, the small volume of residual waste solution and solids made this concentration difficult to achieve. To concentrate the solids, we decanted as much supernate as possible from the centrifuged solids and then added the desired volume of supernate back to the solids to prepare a $2 \mathrm{wt} \%$ solids concentration. The mass of solids present was calculated assuming that the centrifuged volume of test solution contained the target concentration of MST added during the adsorption tests (i.e., if $0.4 \mathrm{~g} / \mathrm{L}$ MST was added in the adsorption test, then the residual adsorption test volume contained $0.4 \mathrm{~g} / \mathrm{L}$ MST solids). The actual mass of the centrifuged solids weigh significantly more than calculated since the residual solids were wet. Also recall that the residual test solutions with the solids were stored at room temperature for 152 days between the adsorption and desorption tests. The decanted residual supernate from each test was sampled and analyzed to determine both the amount of Sr and Pu loaded on the MST during its 152 days of storage as well as the residual soluble concentration added back to the centrifuged MST solids. 

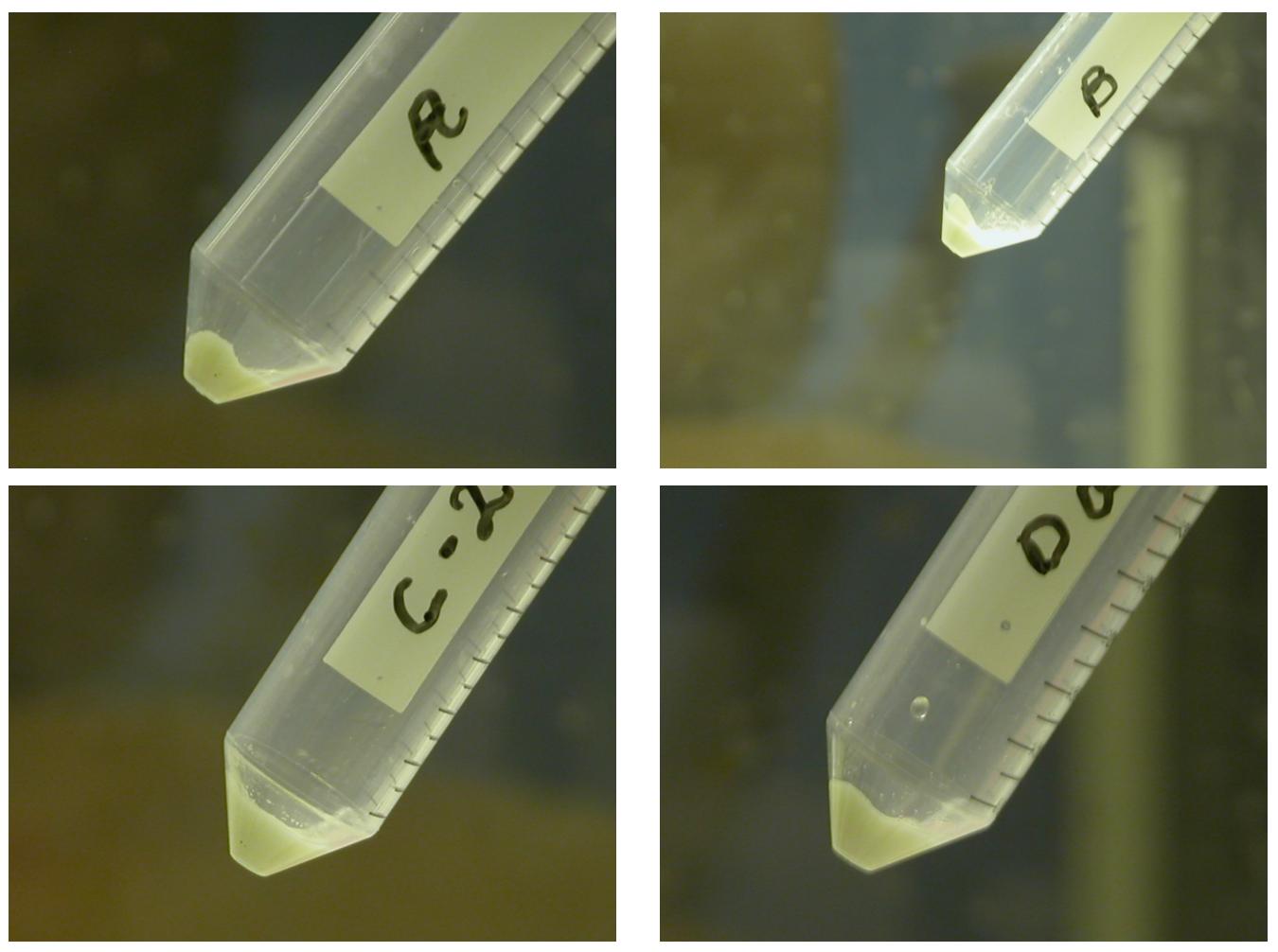

Figure 3-2 Residual MST (Post-Centrifuging) Solids prior to Desorption Testing

The residual solids and supernate were kept in the centrifuge tube and diluted with distilled, deionized water (rather than inhibited or process water as expected for the facility) to simulate washing of the solids. The exact level of dilution was based upon the amount of water required to reduce the residual supernate's measured sodium concentration $(5.6 \mathrm{M})$ to a theoretical final sodium concentration of $0.5 \mathrm{M}$ (i.e., approximately an 11 fold dilution). After dilution, the residual material was continuously shaken using an orbital shaking $(\sim 175$ rpm) bath at a constant temperature of $25 \pm 3{ }^{\circ} \mathrm{C}$. The tests were sampled at $4 \mathrm{~h}, 8 \mathrm{~h}, 12 \mathrm{~h}$, and $24 \mathrm{~h}$. The sample procedure was similar to that outlined in the simulant adsorption tests except volumes and dilutions were adapted for the smaller test volumes. Sample volumes were either 1 or $2 \mathrm{~mL}$ and dilution factors were either 5 or 2.5 , respectively. Dilution was achieved using $2 \mathrm{M} \mathrm{HNO}_{3}$. Samples were submitted for analysis by PuTTA and gamma analysis for ${ }^{85} \mathrm{Sr}$.

\subsubsection{Actual Waste Adsorption Testing}

Testing with actual high-level waste represented the second part of this task. Much of the test methods and parameters duplicated those from the simulant adsorption testing. Testing of multiple MST concentrations, multiple MST strikes, and intermediate filtration to remove residual MST was repeated. Additionally, the same filter types and size $(0.1 \mu \mathrm{PVDF}$ and PES filters) were used both for sampling and intermediate filtration. Actual waste samples from Tank $39 \mathrm{H}$ were provided to SRTC for two tasks - this task as well as supernate characterization for the SWPF. The samples (HTF-E 82-86) arrived July 10-11, 2003 at SRTC. The as-received waste samples were combined, sampled, and analyzed for both 
sodium and anions by inductively coupled plasma-emission spectroscopy (ICP-ES) and ion chromatography (IC). At the time this document is being written, a comprehensive characterization of the waste is being performed by M. E. Stallings ${ }^{3}$ and as such was not repeated in this scope of work.

The sodium concentration of the as-received waste was $6.7 \pm 0.3 \mathrm{M}$. The waste solution was diluted (in two steps) with $1.66 \mathrm{M} \mathrm{NaOH}$ to produce a 5.6 M sodium salt solution. The 5.6 $\mathrm{M} \mathrm{Na}$ waste equilibrated for 12 weeks prior to its use in adsorption testing. The waste solution was sampled periodically during the twelve weeks to monitor the stability of $\mathrm{Sr}$ and actinides. Sampling involved pulling approximately $4.0 \mathrm{~mL}$ of the test solution into a disposable $10-\mathrm{mL}$ syringe and filtering the sample mixture through a $0.1-\mu \mathrm{m}$ syringe filter disk (PVDF) and into a sample bottle. One milliliter portions of each filtered sample were pipetted into a second sample bottle containing $49 \mathrm{~mL}$ of $2 \mathrm{M} \mathrm{HNO}_{3}$. The diluted, acidified sample was manually shaken for approximately 15 seconds and then allowed to equilibrate for a minimum of 2 hours prior to submittal for analysis. Samples were analyzed for ${ }^{237} \mathrm{~Np}$, $\mathrm{U},{ }^{238} \mathrm{Pu},{ }^{239 / 240} \mathrm{Pu},{ }^{241} \mathrm{Am}$, and ${ }^{90} \mathrm{Sr}$ concentrations by ICP-MS, PuTTA, and radiochemical methods. The soluble concentrations of ${ }^{90} \mathrm{Sr}$ and the actinides during the 12 weeks of equilibration are shown in Figure 3-3. Concentrations measured during equilibration and at the start of testing are shown in Table 3-4.

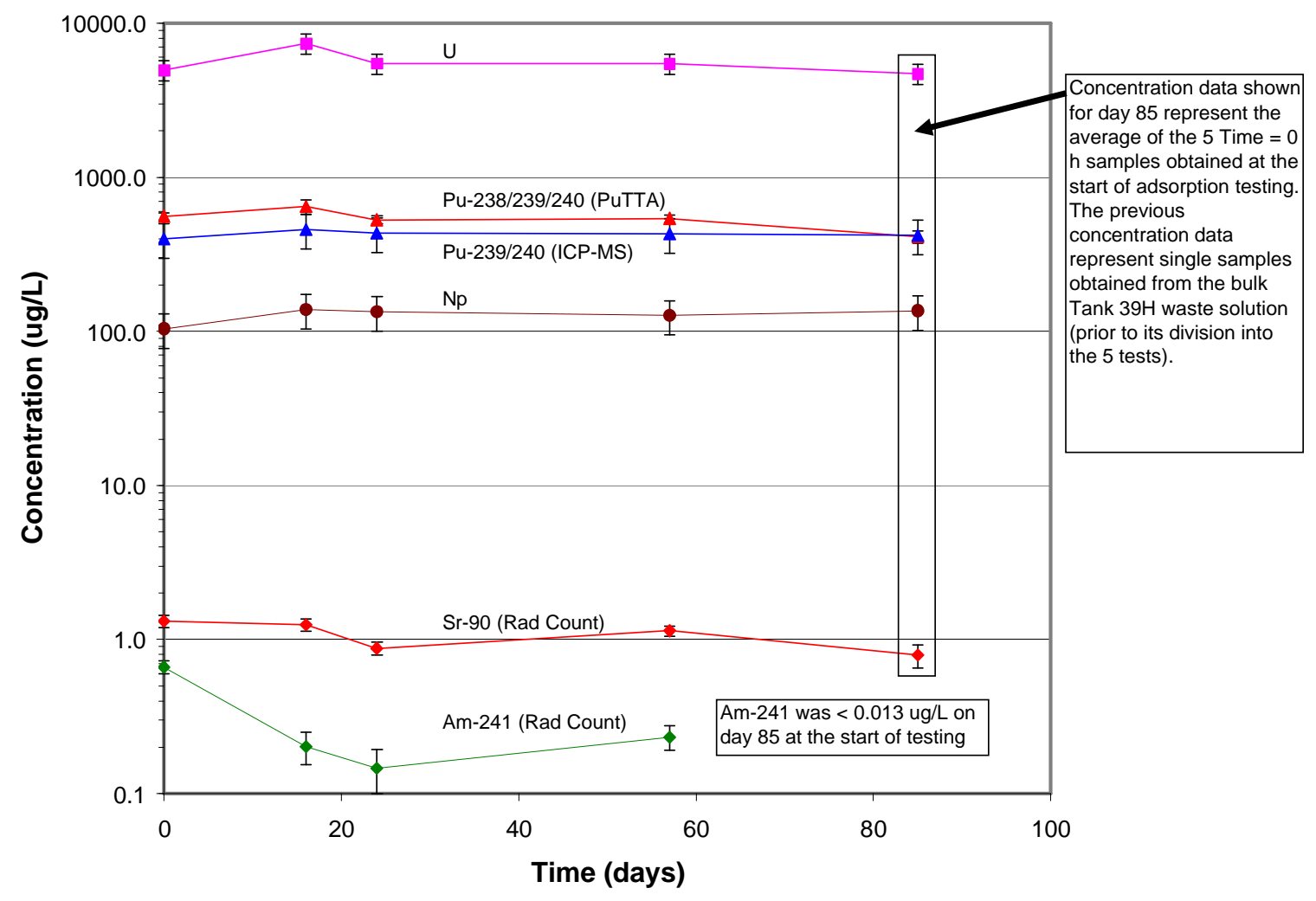

Figure 3-3 Equilibration of Tank 39H Waste Feed Solution 
WSRC-TR-2004-00145, REV. 0

Table 3-4 Equilibration of Soluble Strontium and Actinides in Tank 39H Waste Solution

\begin{tabular}{|c|c|c|c|c|c|c|}
\hline \multirow{2}{*}{$\begin{array}{c}\text { TIME } \\
\text { (days) }\end{array}$} & \multicolumn{7}{|c|}{$\begin{array}{c}\text { Concentration }(\mu \mathrm{g} / \mathrm{L}) \\
\text { (Rad Count) }\end{array}$} & $\begin{array}{c}\text { Total Pu } \\
(\text { PuTTA) }\end{array}$ & $\begin{array}{c}\text { Pu-239/240 } \\
(\text { ICP-MS) }\end{array}$ & $\begin{array}{c}\text { Np-237 } \\
(\text { ICP-MS) }\end{array}$ & $\begin{array}{c}\text { Total U } \\
(\text { ICP-MS) }\end{array}$ & $\begin{array}{c}\text { Am-241 } \\
(\text { Rad Count })\end{array}$ \\
\hline 0 & $1.31 \pm 0.12$ & $560 \pm 29$ & $397 \pm 60$ & $104 \pm 16$ & $4960 \pm 744$ & $0.663 \pm 0.063$ \\
16 & $1.25 \pm 0.12$ & $647 \pm 70$ & $459 \pm 69$ & $139 \pm 21$ & $7400 \pm 1110$ & $0.202 \pm 0.048$ \\
24 & $0.878 \pm 0.081$ & $530 \pm 31$ & $434 \pm 65$ & $134 \pm 20$ & $5480 \pm 822$ & $0.147 \pm 0.046$ \\
57 & $1.14 \pm 0.08$ & $542 \pm 29$ & $431 \pm 65$ & $127 \pm 19$ & $5460 \pm 819$ & $0.233 \pm 0.043$ \\
$85^{*}$ & $0.791 \pm 0.134$ & $411 \pm 39$ & $421 \pm 63$ & $136 \pm 3$ & $4690 \pm 50$ & $<0.013$ \\
\hline
\end{tabular}

*Adsorption testing started on day 85. Data shown represents the average of 5 Time $=0 \mathrm{~h}$ samples and the reported error is their standard deviation.

Examination of Figure 3-3 shows that the soluble concentration of ${ }^{241} \mathrm{Am}$ was not stable prior to testing. The cause of the significant drop after day 58 is unknown. The decrease may result from the use of AMP in the last feed samples and that the AMP improved filtration and removed fine particulate Am. Alternatively, the decrease may result from slow precipitation of Am lasting nearly 60 days similar to that observed for simulated waste [see Figure 3-1]. Neptunium, uranium, and plutonium all show fairly stable soluble concentrations prior to testing. The ${ }^{90} \mathrm{Sr}$ concentration shows a small degree of instability.

Actual waste MST adsorption experiments used the test protocols A, B, E, G, and $\mathrm{H}$ shown in Table 3-5. Protocols A, B, and E duplicated experiments from the simulant adsorption testing. However, Test $\mathrm{E}$ was not conducted in duplicate (as was done with simulant). Testing occurred in the SRTC Shielded Cells Facility. Testing used 250-mL polyethylene bottles fitted with a cap. Researchers prepared each test by placing $120 \mathrm{~mL}$ of the equilibrated simulant solution in the bottle. The desired amount of MST was added to each test using pre-dosed aliquots at the appropriate time (i.e., post-sampling and filtration for the multi-strike tests $\mathrm{E}$ and $\mathrm{H}$ and at $0 \mathrm{~h}$ for the remaining experiments). The MST came from Optima Batch \#00-QAB-417 (as in the simulant testing). Sample bottles were continuously stirred (magnetically) in a water bath at a constant temperature of $25 \pm 4{ }^{\circ} \mathrm{C}$. Figure 3-4 is a photograph of the waterbath apparatus prior to installation in the SRTC Shielded Cells. For those tests $(\mathrm{E}$ and $\mathrm{H})$ involving intermediate filtration, the residual (post-sampling) bulk test solutions were filtered through $0.1 \mu$ PES disposable cup filters. (For Test $\mathrm{H}$, the test solution was centrifuged prior to filtration to collect the first strike MST solids for desorption testing - see Section 3.1.4). Sampling involved removing a test bottle from the waterbath, manually shaking to produce a homogeneous mixture, pulling approximately $7.0 \mathrm{~mL}$ of the test mixture into a disposable $10-\mathrm{mL}$ syringe, and filtering the sample mixture through a 0.1$\mu \mathrm{m}$ syringe filter disk (PVDF) and into a sample bottle. Five milliliter portions of each filtered sample were pipetted into a second sample bottle containing $20 \mathrm{~mL}$ of $2 \mathrm{M}$ nitric acid. The diluted, acidified samples were manually shaken for approximately 15 seconds and then allowed to equilibrate for a minimum of 2 hours.

Prior to this testing, work was performed with simulants using ammonium molybdophosphate (AMP) to assess its affect on various salt solutions. ${ }^{3}$ Previously, the bright yellow powder had been used analytically to remove cesium from waste solutions. 
The results of the testing showed AMP, under the conditions employed, to be effective for removing cesium while not affecting the strontium or actinide concentrations. ${ }^{4}$ Since the AMP demonstration was successful with simulant, DOE requested that the researchers use AMP as part of this task's sample analysis protocols. The methodology involved transferring the diluted, acidified ( $\sim \mathrm{M}$ residual acid) sample to a second sample bottle which contained $\operatorname{AMP}(0.002 \mathrm{~g} / \mathrm{mL})$. The mixture was manually shaken for $\sim 30$ seconds and then immediately filtered using a $0.45 \mu$ disposable cup filter (cellulose nitrate membrane). The filtered samples were then analyzed for ${ }^{237} \mathrm{~Np}, \mathrm{U},{ }^{238} \mathrm{Pu},{ }^{239 / 240} \mathrm{Pu},{ }^{241} \mathrm{Am}$, and ${ }^{90} \mathrm{Sr}$ concentrations by ICP-MS, PuTTA, and radiochemical methods.

\section{Table 3-5 Actual Waste Adsorption Test Protocols}

\begin{tabular}{|c|c|}
\hline Test ID & Description \\
\hline $\mathrm{A}$ & $\begin{array}{l}\text { Addition of } 0.4 \mathrm{~g} / \mathrm{L} \text { MST with sample analysis at } 0,6 \text {, } \\
12,24,48 \text {, and } 168 \mathrm{~h} \text {. }\end{array}$ \\
\hline B & $\begin{array}{l}\text { Addition of } 0.8 \mathrm{~g} / \mathrm{L} \text { MST with sample analysis at } 0,6 \text {, } \\
12,24,48 \text {, and } 168 \mathrm{~h} \text {. }\end{array}$ \\
\hline $\mathrm{E}$ & $\begin{array}{l}\text { Add } 0.4 \mathrm{~g} / \mathrm{L} \mathrm{MST} \text { (incrementally) at } 0,6 \text {, and } 12 \mathrm{~h} \text { with } \\
\text { filtration }(0.1 \mu \mathrm{m}) \text { prior to the second and third MST } \\
\text { strikes and with sample analysis at } 0,6,12,24,36,48, \\
\text { and } 168 \mathrm{~h}(\text { prior to filtrations and incremental additions } \\
\text { at } 6 \text { and } 12 \mathrm{~h} \text { ). }\end{array}$ \\
\hline G & $\begin{array}{l}\text { Control - no addition of MST with sample analysis at } 0 \text {, } \\
6,12,24 \text {, and } 168 \mathrm{~h} \text {. }\end{array}$ \\
\hline $\mathrm{H}$ & $\begin{array}{l}\text { Add } 0.2 \mathrm{~g} / \mathrm{L} \mathrm{MST} \text { (incrementally) at } 0,6 \text {, and } 12 \mathrm{~h} \text { with } \\
\text { filtration }(0.1 \mu \mathrm{m}) \text { prior to the second and third MST } \\
\text { strikes and with sample analysis at } 0,6,12,24 \text {, and } 168 \\
\mathrm{~h} \text { (prior to filtrations and incremental additions at } 6 \text { and } \\
12 \mathrm{~h} \text { ). }\end{array}$ \\
\hline
\end{tabular}

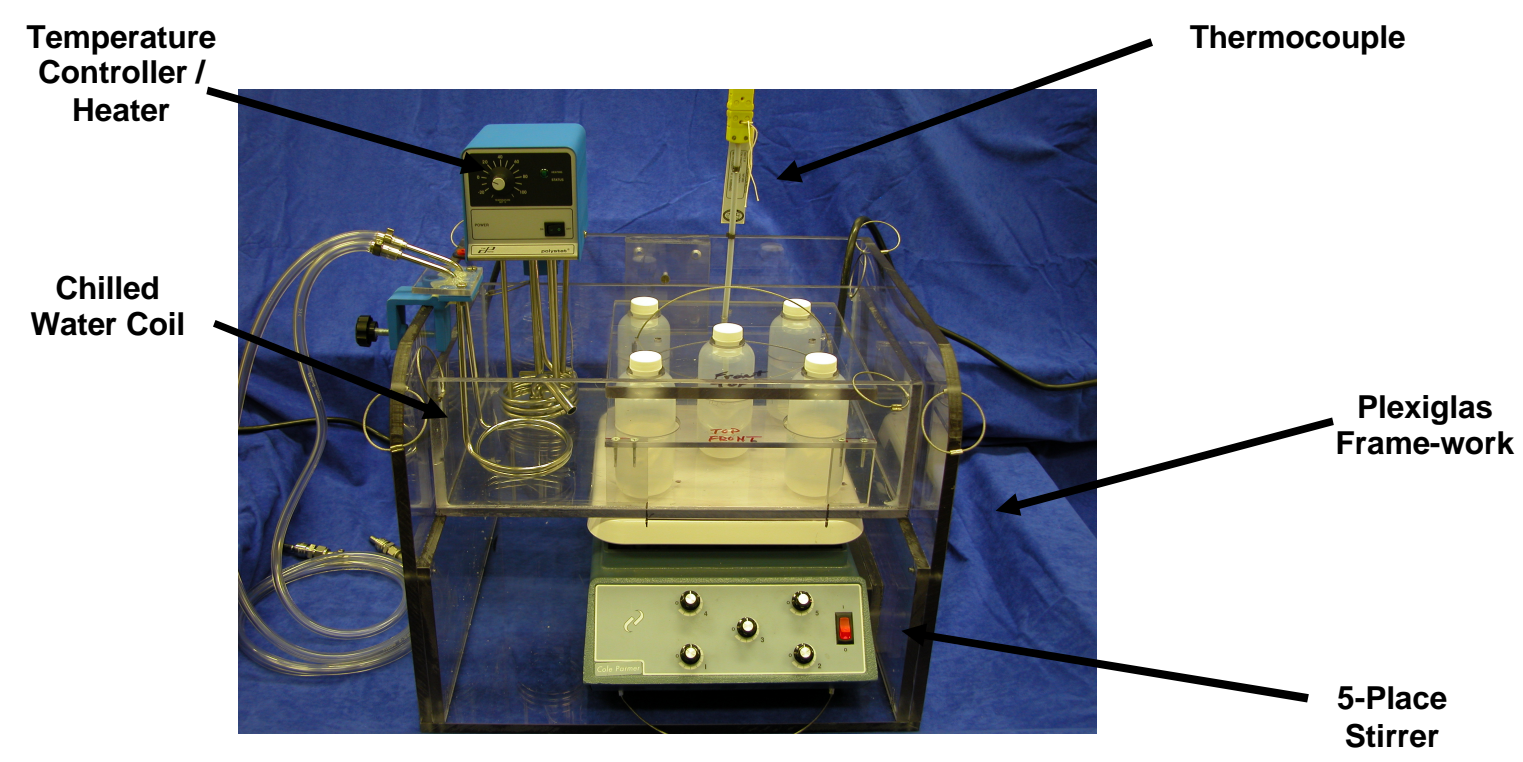

Figure 3-4 Actual Waste Adsorption Test Equipment

\section{Page 9}




\subsubsection{Actual Waste Desorption Testing}

Actual waste desorption tests used the residual MST from two of the previous actual waste MST adsorption tests: Test A and the MST solids from the first strike in Test H. In the case of Test $\mathrm{H}$, the solids were held in a $3 \mathrm{~mL}$ sample of its waste solution until after all adsorption tests completed. Similar to the simulant desorption tests, the tests were conducted by concentrating the residual MST solids using a centrifuge (see Figure 3-5). Again, the target solids concentration was $2 \mathrm{wt} \% \mathrm{MST}$. However, the small volume of residual waste solution and solids made this difficult to achieve. As with the simulant testing, we decanted as much supernate as possible off the centrifuged solids and then added the desired volume of supernate back to the solids to prepare a $2 \mathrm{wt} \%$ solids concentration. The mass of solids present was calculated assuming the centrifuged volume of test solution contained the target concentration of MST added during the adsorption tests (i.e., if $0.4 \mathrm{~g} / \mathrm{L} \mathrm{MST}$ was added in the adsorption test, then the residual adsorption test volume contained $0.4 \mathrm{~g} / \mathrm{L}$ MST solids). Unlike the simulant desorption tests, the residual test solutions and centrifuged solids were only held for a period of 1 to 2 weeks between the adsorption and desorption tests. The decanted residual supernate from each test was sampled and analyzed to determine both the amount of Sr and Pu loaded on the MST during its adsorption testing as well as the residual soluble concentration added back to the centrifuged MST solids.

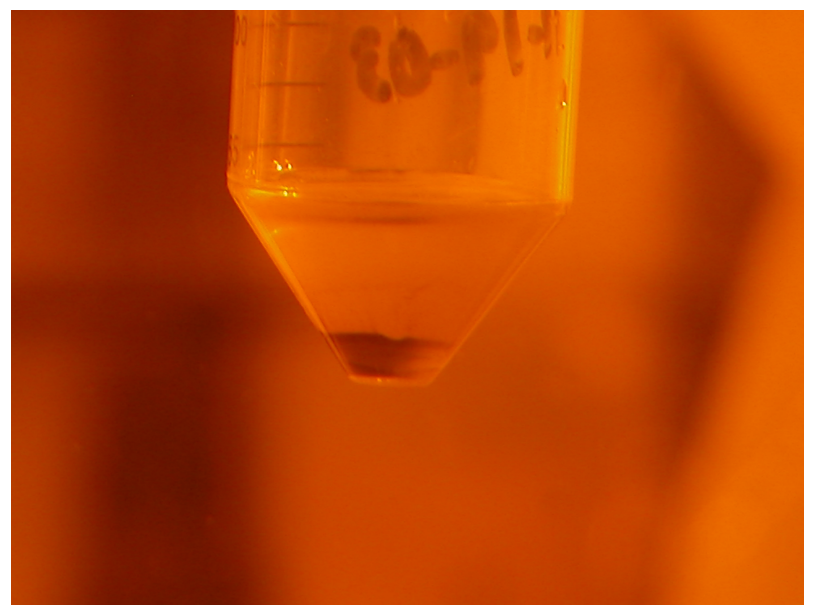

Figure 3-5 Residual MST (Post-Centrifuging) Solids from Test H prior to Desorption Testing

The residual solids and supernate were transferred to a custom-built glass vessel and diluted with distilled, deionized water (rather than inhibited or process water as expected in the facility) to simulate washing of the solids (see Figure 3-6). The exact level of dilution was based upon the amount of water required to reduce the residual supernate's measured sodium concentration $(5.6 \mathrm{M})$ to a theoretical final sodium concentration of $0.5 \mathrm{M}$ (i.e., approximately an 11 fold dilution). After dilution, the residual material was continuously stirred (magnetically) at a constant temperature of $25 \pm 3{ }^{\circ} \mathrm{C}$ in the same apparatus as used in the adsorption tests. The tests were sampled at $4 \mathrm{~h}, 8 \mathrm{~h}, 12 \mathrm{~h}$, and $24 \mathrm{~h}$. The sample procedure was similar to that outlined in the simulant desorption tests. Sampling involved removing a test bottle from the waterbath, manually shaking to produce a homogeneous 
mixture, pulling approximately $2.0 \mathrm{~mL}$ of the test mixture into a disposable $10-\mathrm{mL}$ syringe, and filtering the sample mixture through a $0.1-\mu \mathrm{m}$ syringe filter disk (PVDF) and into a sample bottle. One milliliter portions of each filtered sample were pipetted into a second sample bottle containing $4 \mathrm{~mL}$ of $2 \mathrm{M}$ nitric acid. The diluted, acidified sample was manually shaken for approximately 15 seconds and then allowed to equilibrate for a minimum of 2 hours. Unlike the actual waste adsorption tests, AMP was not employed since the residual cesium concentration was low (due to decanting off the supernate and dilution with water). The filtered samples were analyzed for ${ }^{238} \mathrm{Pu},{ }^{239 / 240} \mathrm{Pu}$, and ${ }^{90} \mathrm{Sr}$ by PuTTA and radiochemical methods.

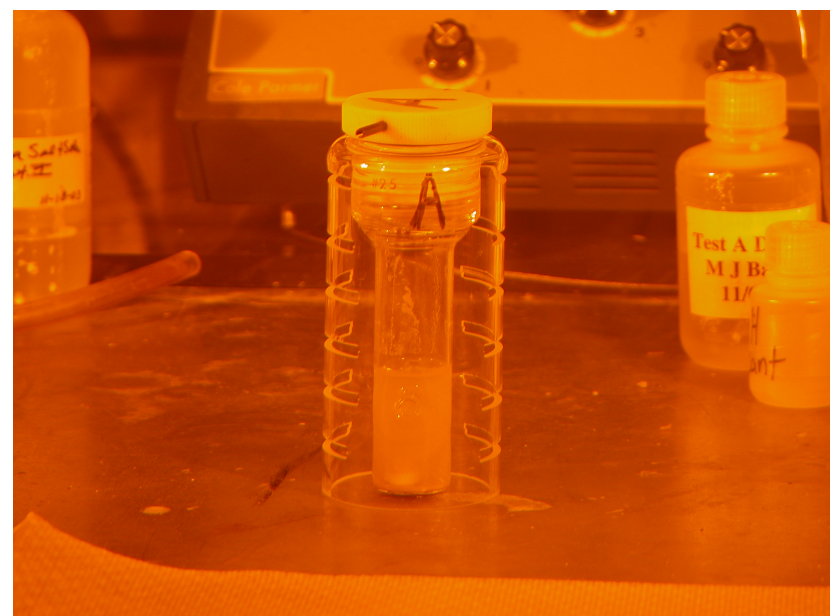

Figure 3-6 Desorption Test Vessel with Residual MST Solids and Diluted Supernate

\subsection{RESULTS}

\subsubsection{Simulant Adsorption Testing}

The objective of both the simulated and actual waste adsorption tests was to investigate the influence of multiple MST additions and the use of intermediate filtration on the efficiency of MST to treat high-level-waste. Simulant testing offered the first attempt at understanding the effect of these parameters. Radioactivity and mass concentration data from the tests are contained in the Appendix (see Table 7-1 and Table 7-2, respectively). Note that uranium data are not provided in the first table since its radioactivity concentration is so low. Figure 3-7 through Figure 3-14 provides graphical representation of the data for the actinides as well as ${ }^{85} \mathrm{Sr}$. A close examination of the Pu data in Figure 3-8 indicates that use of multi-strikes alone does not influence $\mathrm{Pu}$ adsorption or significantly improve the process cycle time (i.e., two strikes of $0.4 \mathrm{~g} / \mathrm{L}$ MST yield a similar solution concentration as a single strike of $0.8 \mathrm{~g} / \mathrm{L}$ MST, likewise three strikes of $0.4 \mathrm{~g} / \mathrm{L}$ MST yield a similar solution concentration as a single strike of $1.2 \mathrm{~g} / \mathrm{L}$ MST). Comparison of the Pu data also indicates that increasing the MST concentration alone provides minimal cycle time improvement. However, Figure 3-7 effectively demonstrates that the use of intermediate filtration between MST strikes does significantly increase the total amount of Pu sorbed by the cumulative MST. The cause of this increase is presumably due to the removal of sorbed $\mathrm{Pu}$ from the solution, thus shifting the adsorption curve to a lower starting Pu concentration (i.e., providing a conventional "stage efficiency" for sequential separations).

Page 11 


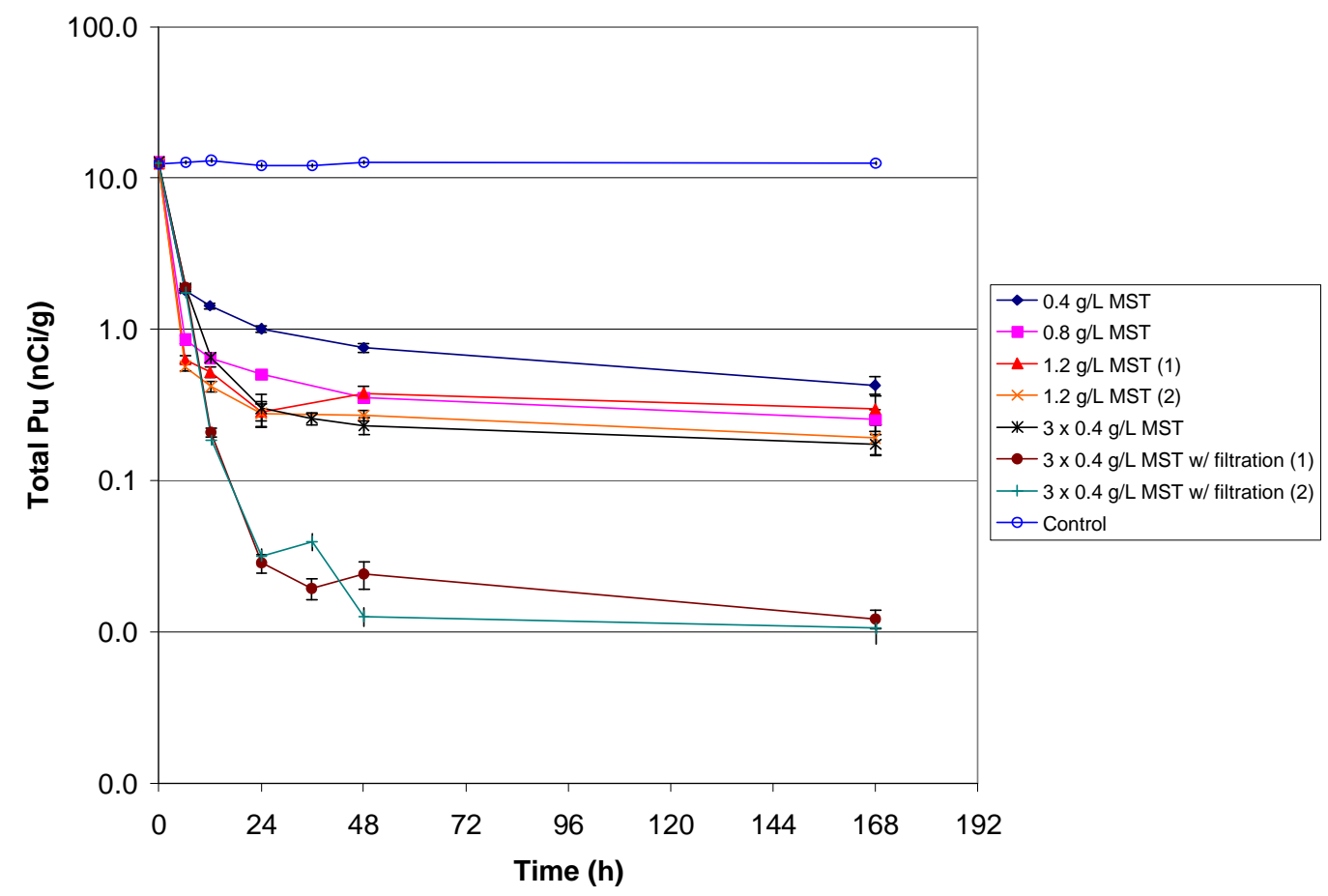

Figure 3-7 Simulant Adsorption Test Plutonium Results

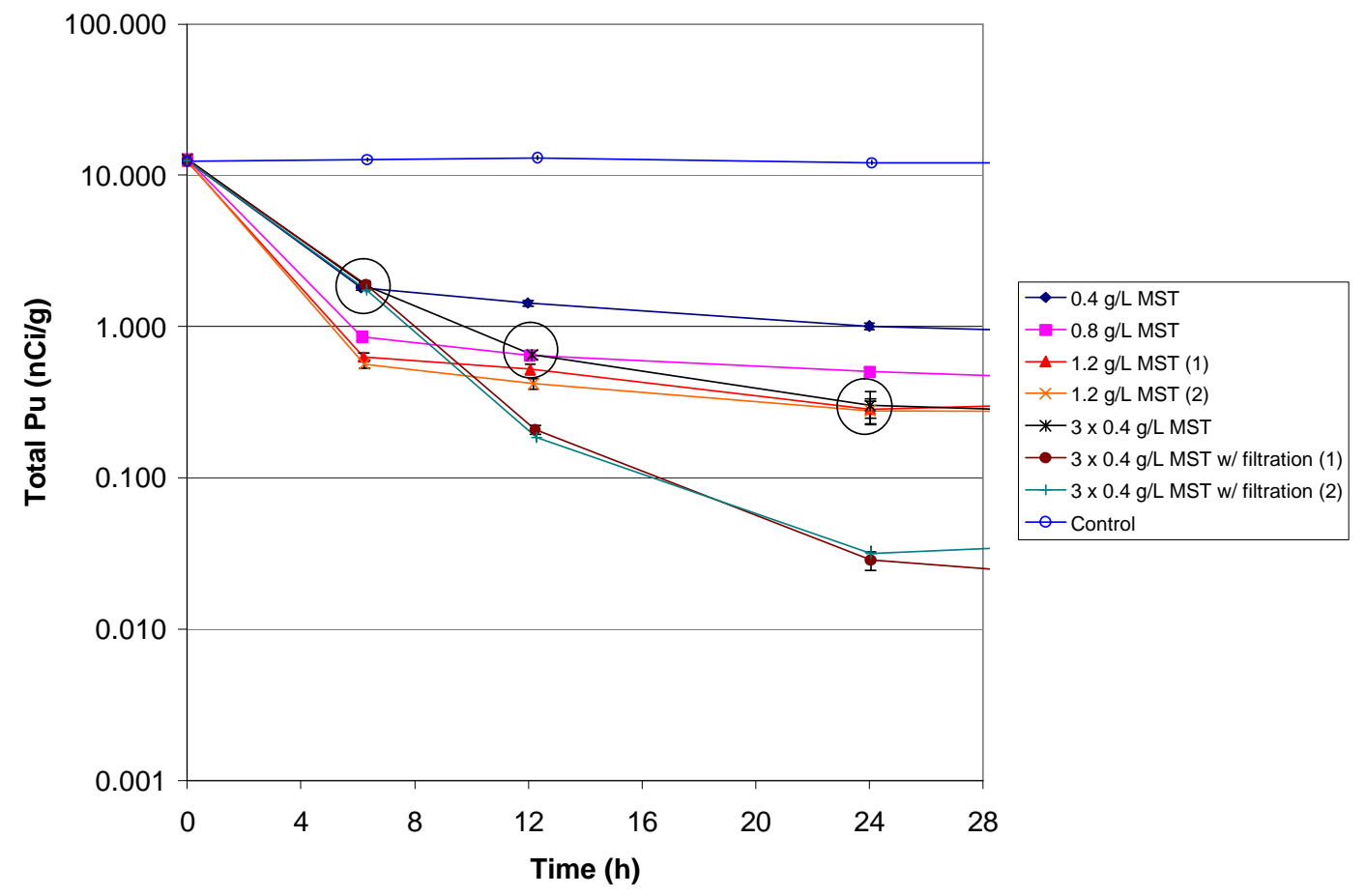

Figure 3-8 Simulant Adsorption Test Plutonium Results - Expanded View 


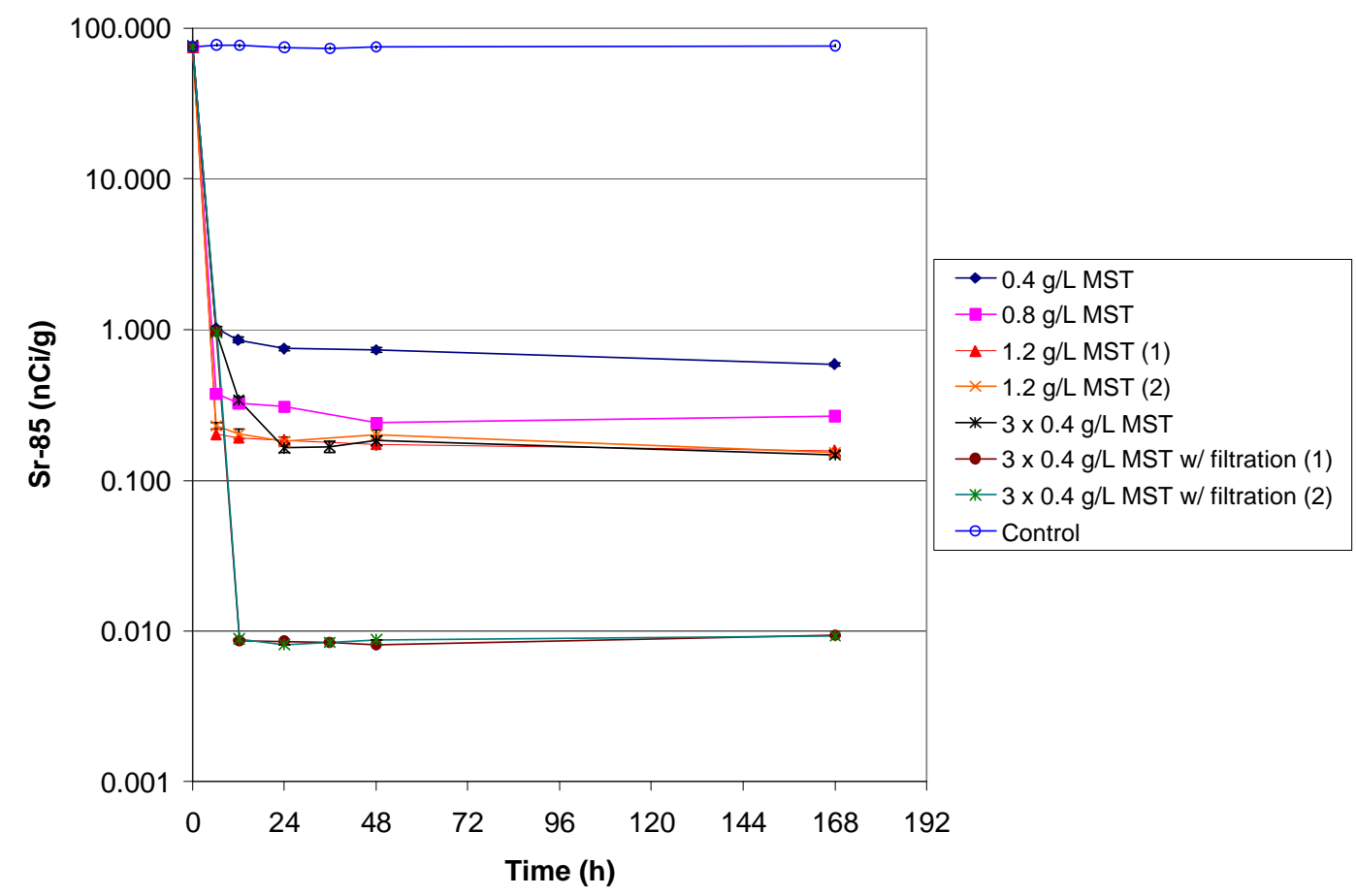

Figure 3-9 Simulant Adsorption Test ${ }^{85} \mathrm{Sr}$ Results

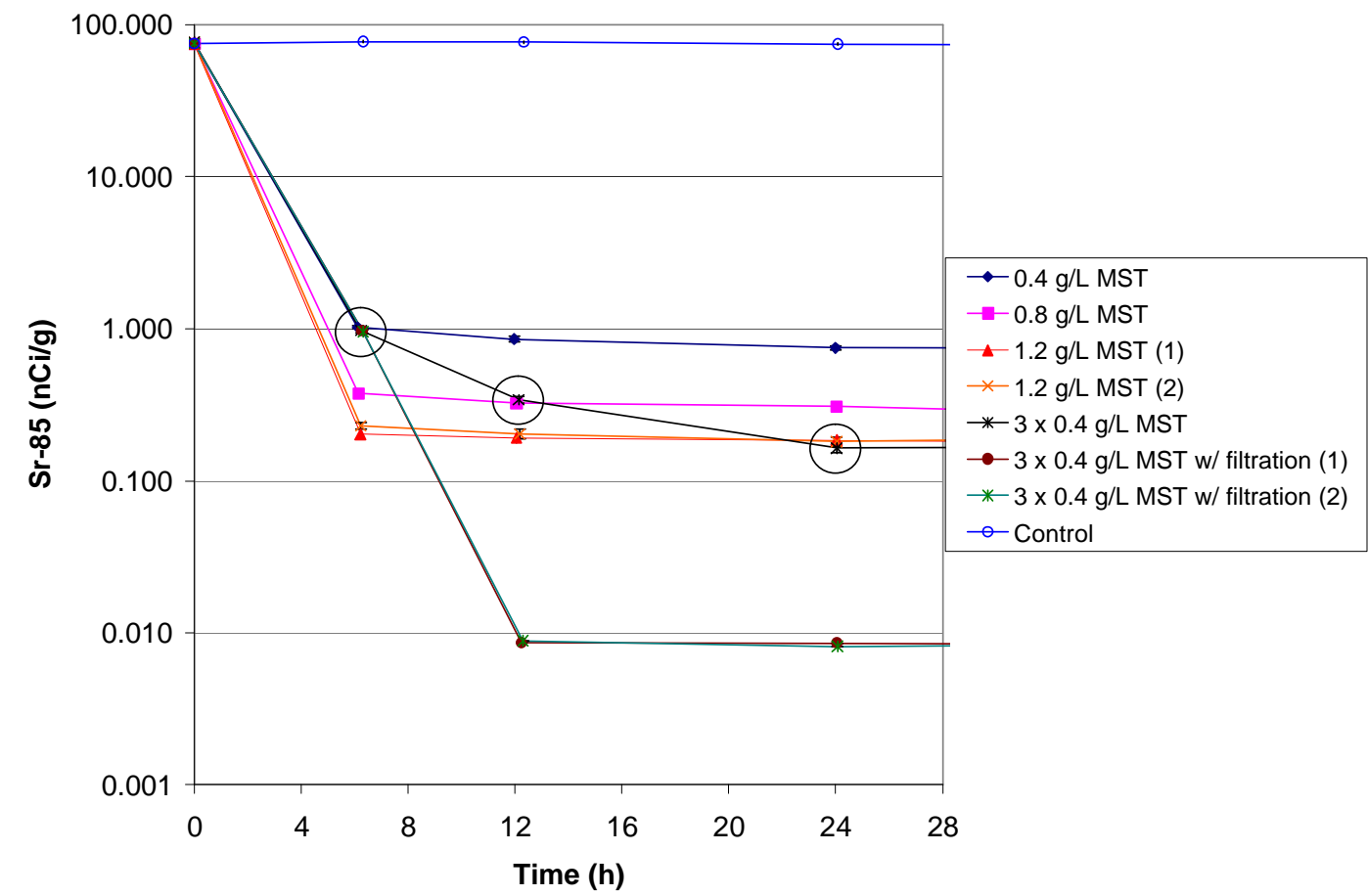

Figure 3-10 Simulant Adsorption Test ${ }^{85} \mathrm{Sr}$ Results - Expanded View

\section{Page 13}




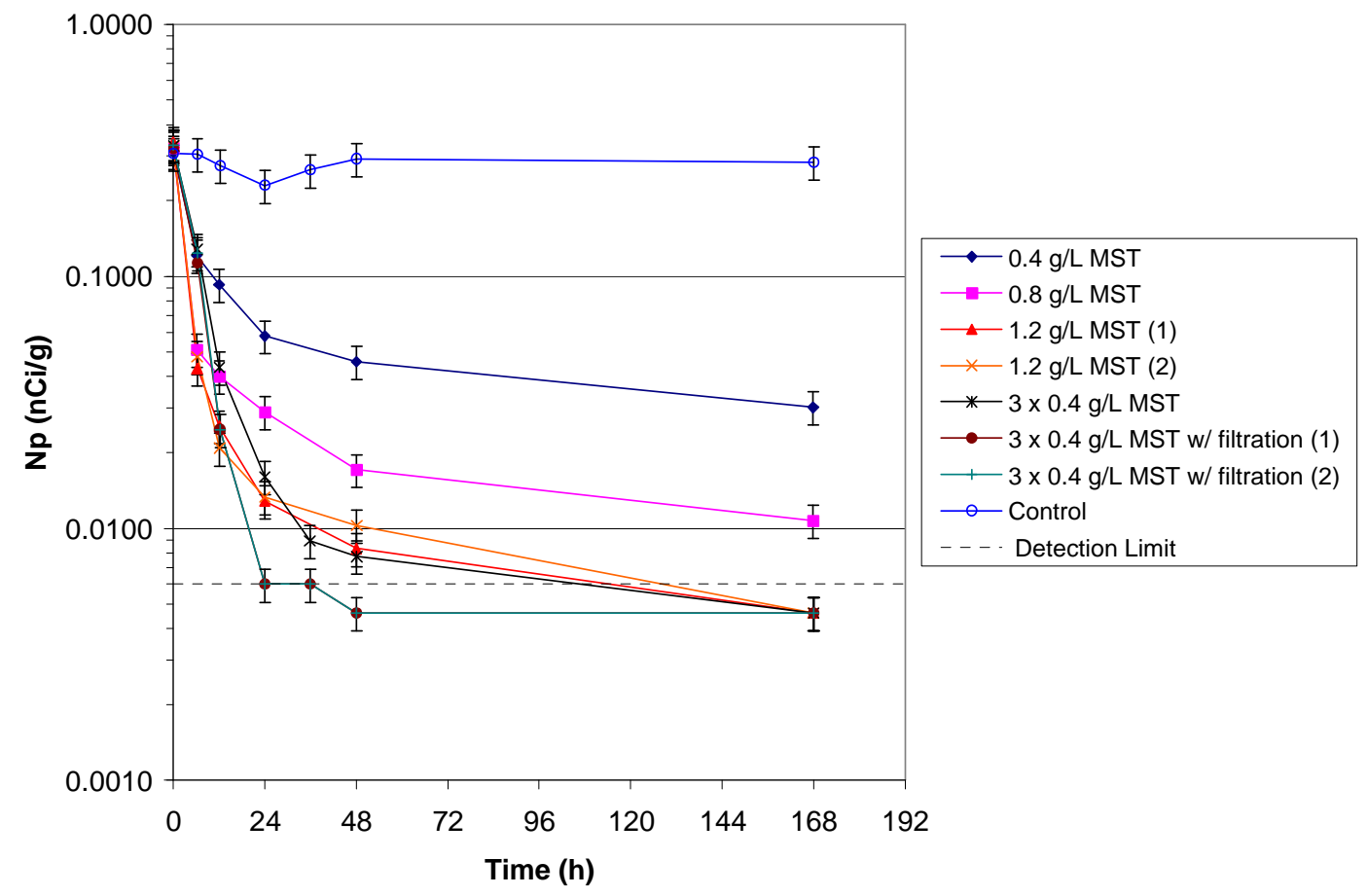

Figure 3-11 Simulant Adsorption Test ${ }^{237} \mathrm{~Np}$ Results

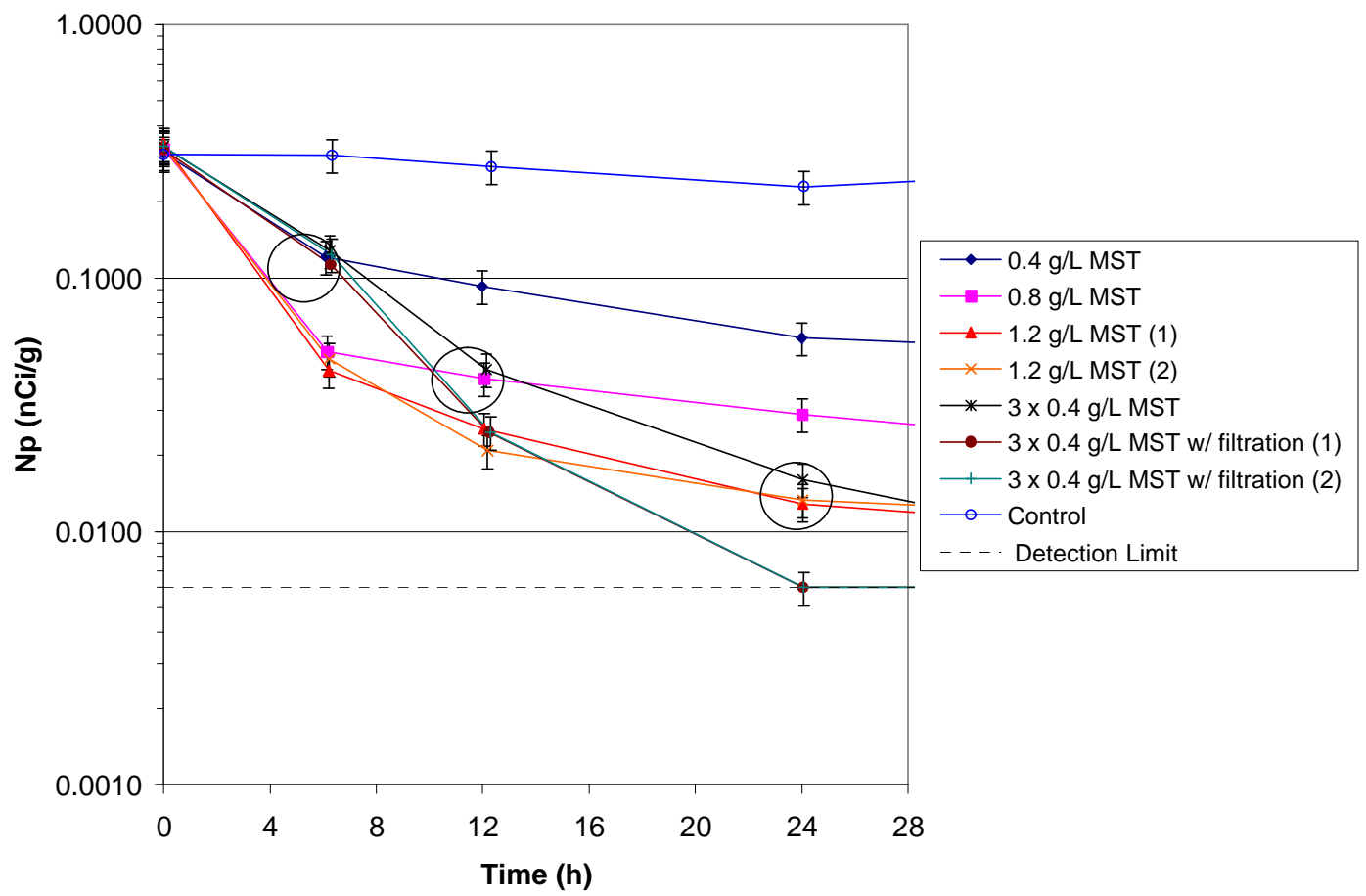

Figure 3-12 Simulant Adsorption Test ${ }^{237} \mathrm{~Np}$ Results - Expanded View 


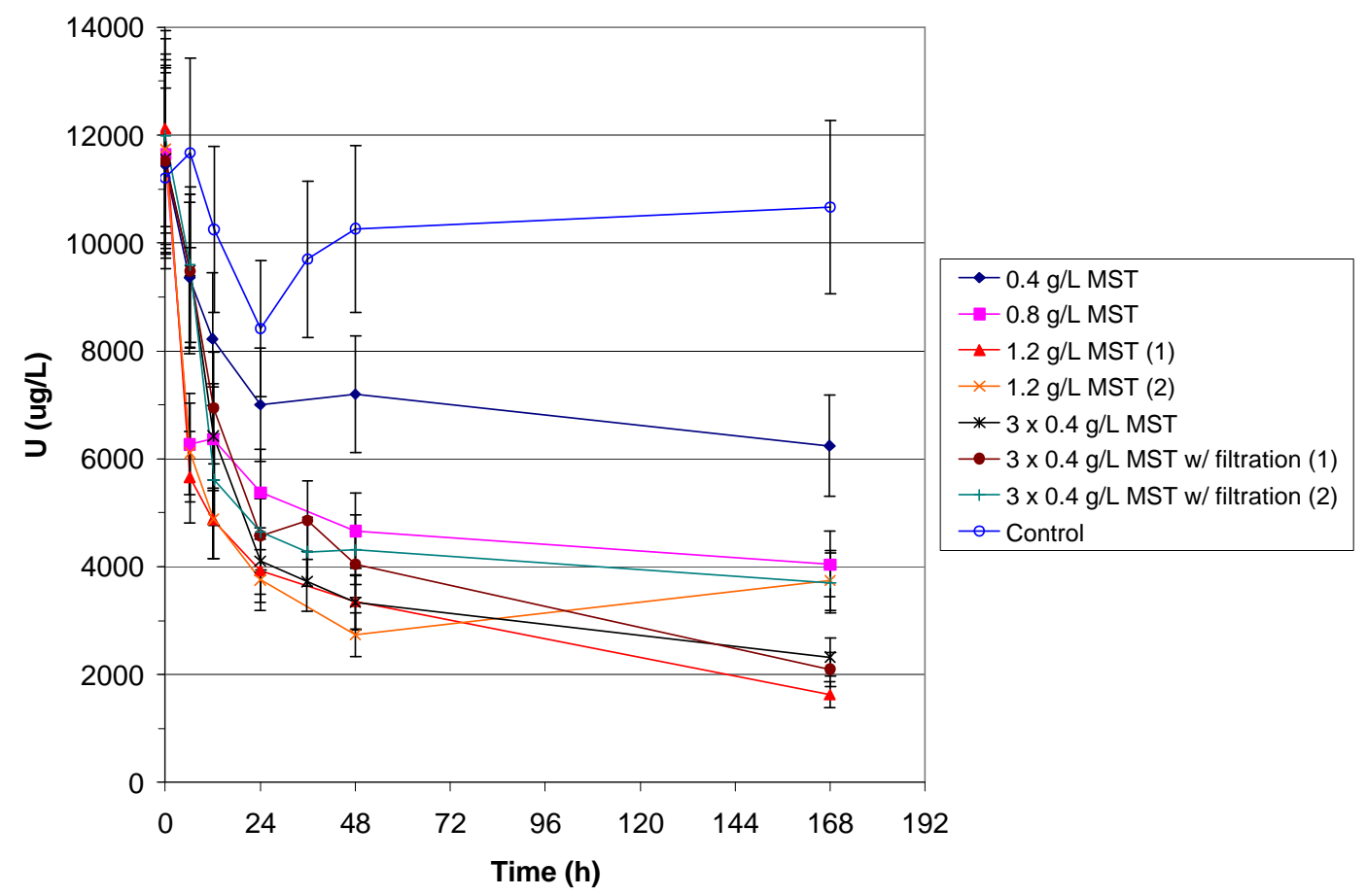

Figure 3-13 Simulant Adsorption Test U Results

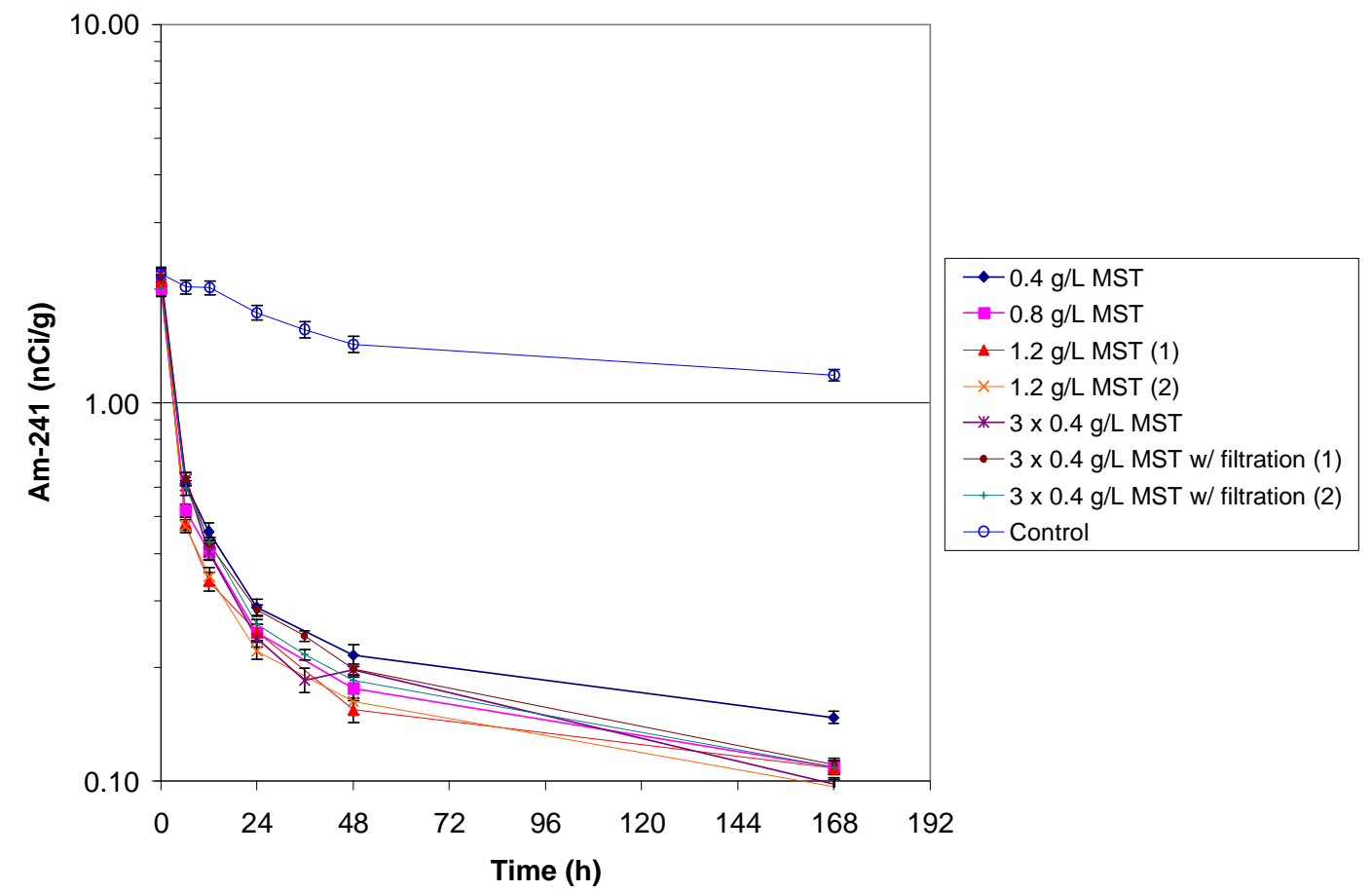

Figure 3-14 Simulant Adsorption Test ${ }^{241}$ Am Results

\section{Page 15}


Figure 3-9 and Figure 3-10 demonstrate the same observations for ${ }^{85} \mathrm{Sr}$ adsorption onto MST. However, the detection limit of ${ }^{85} \mathrm{Sr}$ obscures the full extent of the influence of intermediate filtration on the species. Both data sets showed exceptional agreement between replicates. Figure 3-11 and Figure 3-12 show similar trends for $\mathrm{Np}$ as observed with the $\mathrm{Pu}$ and ${ }^{85} \mathrm{Sr}$ data. However, since the $1.2 \mathrm{~g} / \mathrm{L}$ MST and intermediate filtration test data fall below the detection limit early in the test, the increased influence of intermediate filtration cannot be certain. In the case of uranium, the data shows more variability than the other data sets (this is also due in part to the graph not using a log scale for the $\mathrm{U}$ concentration) as evidenced in Figure 3-13. Similar to the $\mathrm{Pu},{ }^{85} \mathrm{Sr}$, and ${ }^{237} \mathrm{~Np}$ data, the $\mathrm{U}$ data demonstrate that multi-strike is ineffective in increasing removal efficiency. Unlike the other three species, the influence of intermediate filtration was not observed with the $\mathrm{U}$ data. Figure 3-14 shows that the behavior of ${ }^{241} \mathrm{Am}$ is unique among the test species. Little if any increase in sorption from added MST is observed and intermediate filtration was ineffective. The Control test shows a small decrease in soluble ${ }^{241} \mathrm{Am}$ during the testing leading to speculation that the mechanism of ${ }^{241} \mathrm{Am}$ removal is likely due to precipitation rather than adsorption.

Decontamination factors (DFs) were calculated for each of the tests and each Analyte as reported in Table 3-6. Comparison of the DFs between comparable tests is reliable since the tests all used the same simulant and temperature. The DFs reflect the same observations as the graphs. Specifically, that $\mathrm{Pu},{ }^{85} \mathrm{Sr}$, and $\mathrm{Np}$ all show increased adsorption with the combination of increased addition of MST and the use of intermediate filtration. Uranium DFs also demonstrate the increase associated with increased MST addition. However, intermediate filtration did not produce a measurable increase in DF for U. Lastly, ${ }^{241} \mathrm{Am}$ did not demonstrate increase in DF due to either an increase of MST or the use of intermediate filtration.

\section{Table 3-6 Simulant Adsorption Test Decontamination Factors}

\begin{tabular}{|c|c|c|c|c|c|c|c|c|c|c|}
\hline & \multicolumn{2}{|c|}{$\underline{\mathrm{Pu}}$} & \multicolumn{2}{|c|}{$\underline{\mathrm{Sr}-85}$} & \multicolumn{2}{|c|}{$\underline{N p}$} & \multicolumn{2}{|c|}{$\underline{\mathrm{U}}$} & \multicolumn{2}{|c|}{ Am-241 } \\
\hline & $24 \mathrm{~h}$ & $168 \mathrm{~h}$ & $24 \mathrm{~h}^{\top}$ & $168 \mathrm{~h}$ & $24 \mathrm{~h}$ & $168 \mathrm{~h}$ & $24 \mathrm{~h}$ & $168 \mathrm{~h}$ & $24 \bar{h}$ & $168 \mathrm{~h}$ \\
\hline $0.4 \mathrm{~g} / \mathrm{L}$ MST & 13 & 30 & 100 & 130 & 5.4 & 10 & 1.6 & 1.8 & 7.3 & 14 \\
\hline $0.8 \mathrm{~g} / \mathrm{L}$ MST & 27 & 52 & 240 & 280 & 11 & 30 & 2.2 & 2.9 & 8.1 & 18 \\
\hline $1.2 \mathrm{~g} / \mathrm{L}$ MST (avg) & 44 & 55 & 410 & 490 & 26 & 72 & 3.1 & 5.3 & 9.1 & 21 \\
\hline $3 \times 0.4 \mathrm{~g} / \mathrm{L}$ MST & 44 & 74 & 470 & 520 & 21 & 72 & 2.8 & 5.0 & 9.2 & 22 \\
\hline $3 \times 0.4 \mathrm{~g} / \mathrm{L}$ MST filtered (avg) & 450 & 1190 & 9010 & 8050 & 55 & 71 & 2.6 & 4.4 & 7.6 & 19 \\
\hline Control & 1.0 & 1.0 & 1.0 & 1.0 & 1.3 & 1.1 & 1.3 & 1.0 & 1.3 & 1.9 \\
\hline
\end{tabular}

\subsubsection{Simulant Desorption Testing}

The release of sorbed $\mathrm{Sr}$ and actinides from loaded MST during the washing stages in the SWPF is of concern. Desorption tests were performed to assess this potential problem using loaded MST from four of the previous MST adsorption tests: Tests A, B, C (actually Test C2 since duplicate $\mathrm{C}$ adsorption tests were conducted), and $\mathrm{D}$. The use of a centrifuge to concentrate the residual MST solids proved adequate. The target solids concentration and diluted sodium concentrations were obtained with little difficulty. Table 3-7 provides the test characteristics of interest. Specifically, the theoretical maximum $\mathrm{Pu}$ and ${ }^{85} \mathrm{Sr}$ concentrations are well above the instruments' detection limit. The theoretical max concentrations represent 
the maximum concentrations that would result if all of the species desorbed into the washwater. Examination of the data contained in Table 3-8 shows that all but one of the data points are below the instrumental detection limit. While the exact value of each species released is unknown, the less than values serve to bound the release rate at a very small value, if any. The magnitude of the detection limit demonstrates that release of sorbed species from loaded MST are well below the Waste Acceptance Criteria (WAC) limits and should not be a problem during washing in the SWPF.

Table 3-7 Simulant Desorption Test Characteristics

\begin{tabular}{|c|c|c|c|c|c|}
\hline Test ID & $\begin{array}{c}\text { Theoretical } \\
\text { Solids } \\
\text { Concentration } \\
\text { (wt\%) }^{*}\end{array}$ & $\begin{array}{c}\text { Pu } \\
\text { Loading } \\
\text { (umole/g MST) }\end{array}$ & $\begin{array}{c}\text { Theoretical } \\
\text { Max [Pu] } \\
\text { (nCi/g)\# }\end{array}$ & $\begin{array}{c}\text { Sr-85 } \\
\text { Loading } \\
\text { (umole/g MST) }\end{array}$ & $\begin{array}{c}\text { Theoretical } \\
\text { Max [Sr-85] } \\
\text { (nCi/g)\# }\end{array}$ \\
\hline A & 2.1 & 2.2 & 88 & $1.1 \mathrm{E}-04$ & 530 \\
\hline B & 2.0 & 1.1 & 45 & $5.7 \mathrm{E}-05$ & 260 \\
\hline C & 2.1 & 0.72 & 29 & $3.9 \mathrm{E}-05$ & 180 \\
\hline D & 2.0 & 0.74 & 30 & $3.9 \mathrm{E}-05$ & 180 \\
\hline
\end{tabular}

*The theoretical solids concentration is calculated from the mass of MST added to the original adsorption test, the residual volume of test solution from the adsorption test, and the volumes of supernate and wash water added to the desorption test.

\#The theoretical maximum $\mathrm{Pu}$ and ${ }^{85} \mathrm{Sr}$ concentrations represent the maximum concentrations that would result if all of the species desorbed into the washwater.

Table 3-8 Simulant Desorption Test Data - Concentration Units of $\mathbf{n C i} / \mathbf{g}$

\begin{tabular}{|c|c|c|c|c|c|}
\hline \multirow[b]{2}{*}{ Test ID } & \multirow{2}{*}{$\begin{array}{l}\text { Reaction } \\
\text { Time (h) }\end{array}$} & \multicolumn{4}{|c|}{ Concentration (nCi/g) } \\
\hline & & ${ }^{85} \mathrm{Sr}$ & \pm & $\mathrm{Pu}$ & \pm \\
\hline Test $\mathrm{A}$ & 0.0 & 0.007 & 0.002 & $<0.02$ & $\overline{m d a}$ \\
\hline Test A & 4.0 & $<0.076$ & mda & $<0.92$ & mda \\
\hline Test A & 8.0 & $<0.068$ & mda & $<0.08$ & mda \\
\hline Test A & 12.0 & $<0.067$ & mda & $<1.34$ & mda \\
\hline Test A & 24.1 & $<0.066$ & mda & $<10.0$ & mda \\
\hline & & & & & \\
\hline Test B & 0.0 & 0.003 & 0.001 & $<0.03$ & mda \\
\hline Test B & 4.1 & $<0.034$ & mda & $<0.19$ & mda \\
\hline Test B & 8.0 & $<0.035$ & mda & $<0.18$ & mda \\
\hline Test B & 12.0 & $<0.016$ & mda & $<0.15$ & mda \\
\hline Test B & 24.1 & $<0.032$ & mda & $<0.42$ & mda \\
\hline & & & & & \\
\hline Test C & 0.0 & $<0.002$ & mda & $<0.02$ & $\mathrm{mda}$ \\
\hline Test C & 4.0 & $<0.035$ & mda & $<11.4$ & mda \\
\hline Test C & 8.0 & $<0.039$ & mda & $<0.16$ & mda \\
\hline Test C & 12.0 & $<0.018$ & mda & $<1.07$ & mda \\
\hline Test C & 24.1 & $<0.031$ & mda & $<0.22$ & mda \\
\hline & & & & & \\
\hline Test D & 0.0 & $<0.002$ & mda & $<0.01$ & mda \\
\hline Test D & 4.0 & $<0.032$ & mda & $<0.20$ & mda \\
\hline Test D & 8.1 & $<0.032$ & mda & $<0.61$ & mda \\
\hline Test D & 12.1 & $<0.018$ & mda & $<0.08$ & mda \\
\hline Test D & 24.1 & $<0.030$ & mda & $<0.12$ & mda \\
\hline
\end{tabular}

\subsubsection{Actual Waste Adsorption Testing}

Actual waste adsorption testing was performed with tank $39 \mathrm{H}$ waste diluted to $5.6 \mathrm{M}$ sodium. Actinide analysis by ICP-MS of the Tank $39 \mathrm{H}$ feed after 12 weeks of testing showed the waste to be unique in composition (see Table 3-9). Analysis shows the waste to contain a 
high percentage of ${ }^{235} \mathrm{U}$ as well as measurable quantities of ${ }^{241} \mathrm{Pu}$ and ${ }^{242} \mathrm{Pu}$. Additionally, the

${ }^{241} \mathrm{Am}$ was determined to be significantly lower than observed in previous feed sample analyses (i.e., sample analyses performed during feed equilibration prior to testing). Speculation is that the difference between earlier feed samples and the equilibrated samples at the start of testing is caused by an AMP filtration effect, although this possible explanation of the difference remains unproven.

\section{Table 3-9 Soluble Actinides Composition of 5.6 M Na Tank 39H Waste}

\begin{tabular}{|c|c|c|}
\hline Mass \# & $\begin{array}{c}\text { Average } \\
\text { Starting } \\
\text { Concentration } \\
\text { (ug/L) }\end{array}$ & $\begin{array}{c}\text { Uncertainty } \\
(\text { ug/L) } \\
(\mathrm{n}=5)\end{array}$ \\
\hline${ }^{234} \mathrm{U}$ & 118 & 5.8 \\
\hline${ }^{235} \mathrm{U}$ & 1491 & 7.7 \\
\hline${ }^{236} \mathrm{U}$ & 476 & 4.0 \\
\hline${ }^{237} \mathrm{~Np}$ & 136 & 2.8 \\
\hline${ }^{238} \mathrm{U}$ & 2608 & 50.3 \\
\hline${ }^{239} \mathrm{Pu}$ & 374 & 12.5 \\
\hline${ }^{240} \mathrm{Pu}$ & 47.1 & 3.6 \\
\hline${ }^{241} \mathrm{Pu}$ & 8.92 & 1.63 \\
\hline${ }^{242} \mathrm{Pu}$ & 38.4 & 2.6 \\
\hline${ }^{241} \mathrm{Am}(\mathrm{Rad})$ & $<0.0134$ & upper limit \\
\hline
\end{tabular}

Actual waste adsorption testing repeated four of the five test protocols from simulant testing. The fifth test involved three additions of $0.2 \mathrm{~g} / \mathrm{L}$ MST with intermediate filtration. The objectives of the tests were the same as that of the simulant testing. Radioactivity and mass concentration data from the tests are contained in the Appendix (see Table 7-3 and Table 7-4, respectively). Note that $U$ data again are not provided in the first table since its radioactivity concentration is so low. Figure 3-15 through Figure 3-17 provides graphical representation of the data for $\mathrm{Pu},{ }^{90} \mathrm{Sr}$, and $\mathrm{U}$. Both ${ }^{237} \mathrm{~Np}$ and ${ }^{241} \mathrm{Am}$ data were not presented graphically since the bulk of their data fell below their detection limits.

Figure 3-15 demonstrates the same findings as observed in simulant adsorption testing. Specifically, increased MST provides for increased adsorption with minimal cycle time improvement. The use of intermediate filtration increased $\mathrm{Pu}$ removal. In fact, only the two multi-strike tests with intermediate filtration reached the $\mathrm{Pu}$ process limit $(18 \mathrm{nCi} / \mathrm{g})$ for this waste within $24 \mathrm{~h}$. Figure 3-16 demonstrates many of the same findings for ${ }^{90} \mathrm{Sr}$, with a few notable exceptions. All tests met the process limit for ${ }^{90} \mathrm{Sr}$. The behavior of the two multistrike tests with intermediate filtration were contrary to common logic (i.e., the $3 \times 0.2 \mathrm{~g} / \mathrm{L}$ MST outperformed the $3 \times 0.4 \mathrm{~g} / \mathrm{L} \mathrm{MST)}$. The cause of this later discrepancy is unknown.

Figure 3-17 shows that $U$ behavior is similar to that observed in the simulant tests.

Specifically, adsorption increased with increasing MST concentration. In the case of ${ }^{237} \mathrm{~Np}$, the low starting concentration prevented full observation of MST test influences (i.e., the detection limits cover the test results). However, results from six hours of testing followed the predicted behavior. 

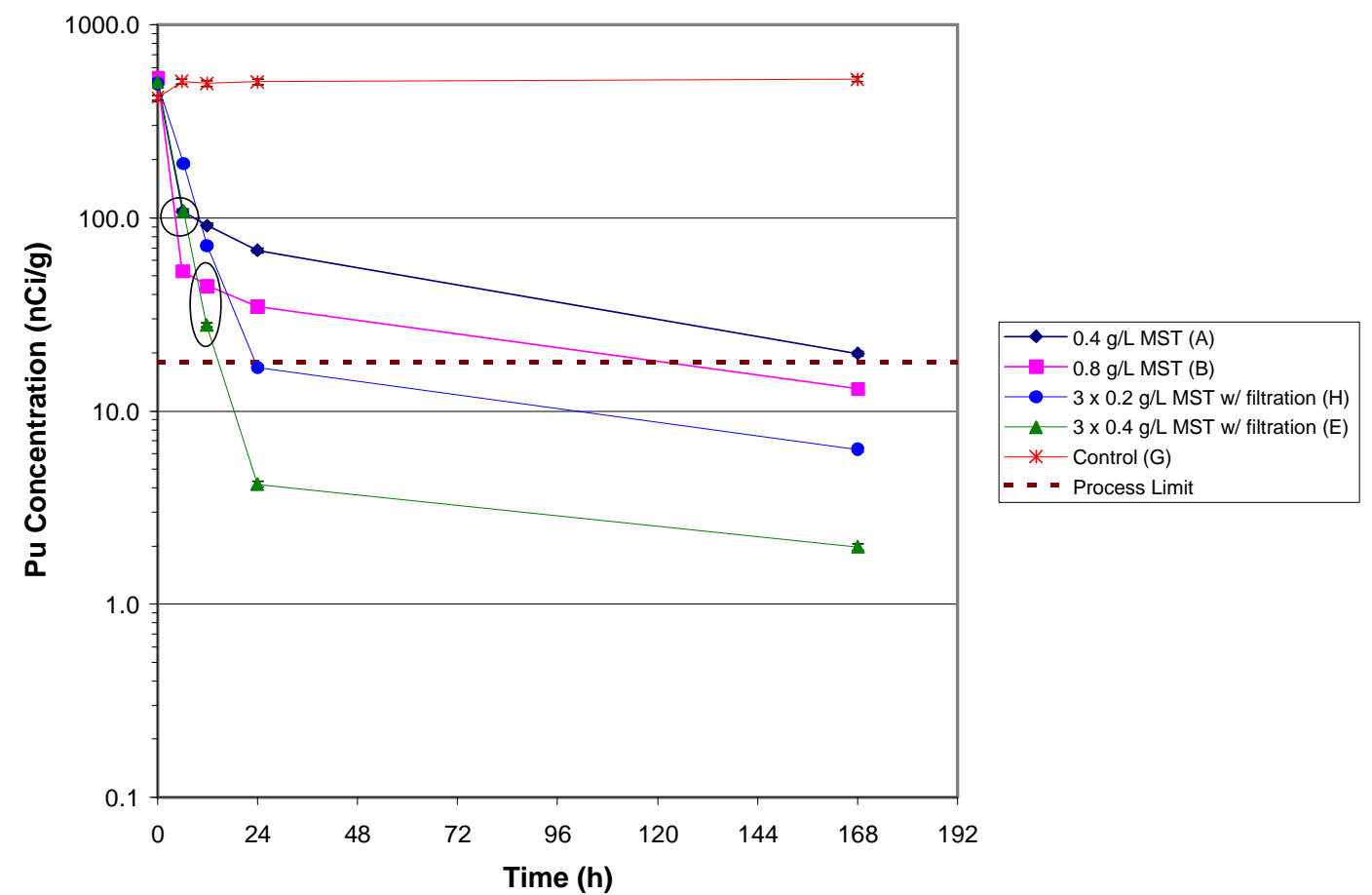

Figure 3-15 Actual Waste Adsorption Test ${ }^{238 / 39 / 40} \mathrm{Pu}$ Results

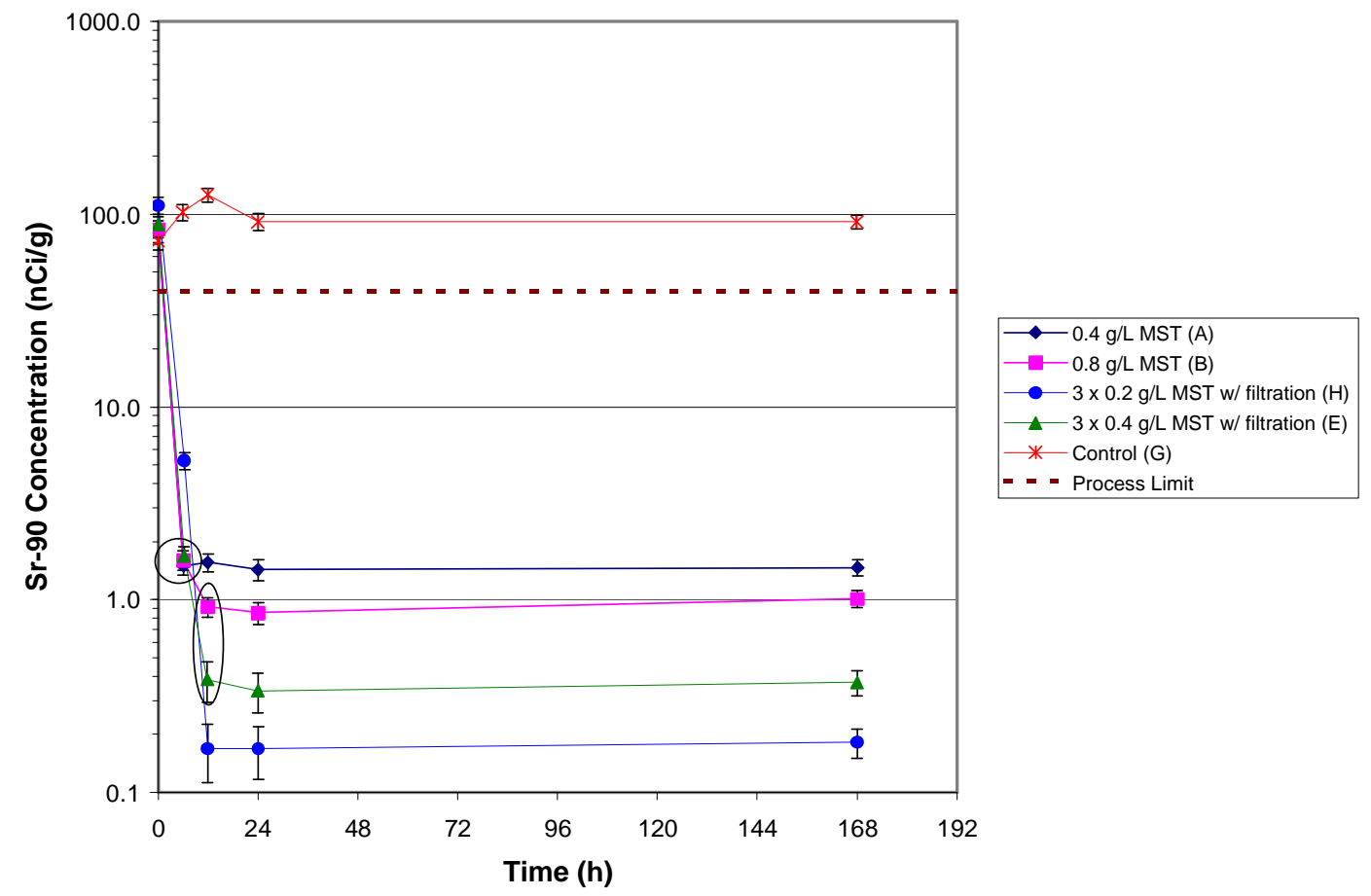

Figure 3-16 Actual Waste Adsorption Test ${ }^{90} \mathrm{Sr}$ Results

\section{Page 19}




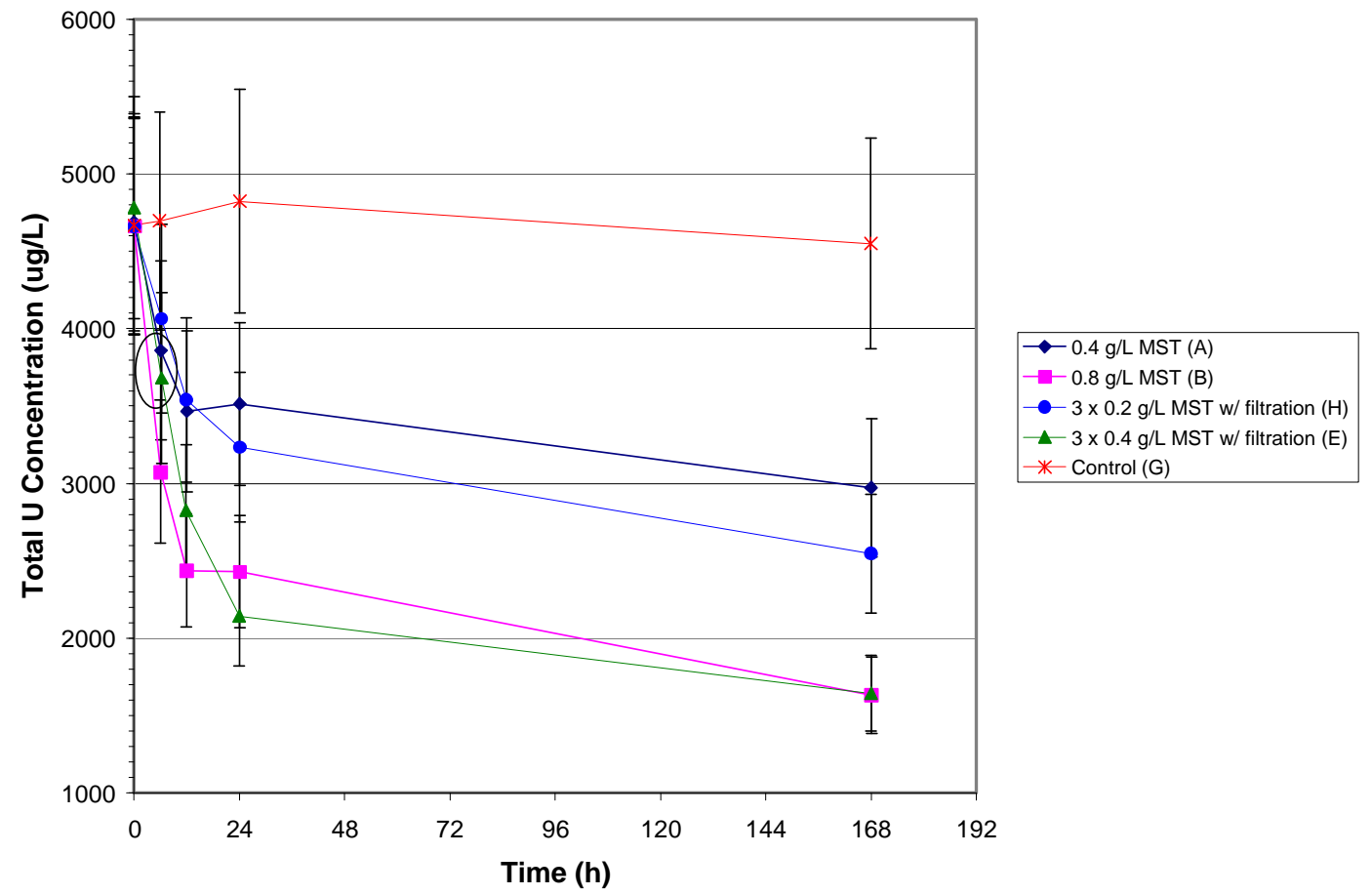

Figure 3-17 Actual Waste Adsorption Test U Results

Decontamination factors were calculated for each analyte as reported in Table 3-10. Again, comparison of the DFs between comparable tests is possible since the tests all used the same starting material and temperature. The DFs reflect the same observations as the graphs. Specifically, that $\mathrm{Pu}$ and ${ }^{90} \mathrm{Sr}$ all show increased adsorption with increased addition of MST and the use of intermediate filtration. Uranium DFs also demonstrate the increase associated with increased MST addition.

Table 3-10 Actual Waste Adsorption Test Decontamination Factors

\begin{tabular}{|c|cc|ccc|}
\hline Test & \multicolumn{2}{|c|}{$\mathbf{P u}$} & \multicolumn{3}{c|}{ Sr-90 } \\
\hline 0.4 g/L MST (A) & 7.8 & $\mathbf{1 6 8} \mathbf{~ h}$ & $\mathbf{2 4} \mathbf{~}$ & $\mathbf{1 6 8} \mathbf{~}$ \\
0.8 g/L MST (B) & 15 & 25 & 55 & 54 \\
$3 \times 0.2$ g/L MST (H) & 33 & 40 & 98 & 83 \\
$3 \times 0.4$ g/L MST (E) & 120 & 320 & 660 & NA \\
Control (G) & 0.86 & 0.81 & 0.80 & 0.80 \\
\hline
\end{tabular}

\begin{tabular}{|c|c|c|c|c|}
\hline \multirow[b]{2}{*}{ Test } & \multicolumn{2}{|c|}{$\mathrm{Np}$} & \multicolumn{2}{|c|}{$\mathbf{U}$} \\
\hline & $6 \mathrm{h \#}$ & $168 \mathrm{~h}$ & $24 \mathrm{~h}$ & $168 \mathrm{~h}$ \\
\hline $0.4 \mathrm{~g} / \mathrm{L}$ MST $(\mathrm{A})$ & 2.1 & $>2.1$ & 1.3 & 1.6 \\
\hline $0.8 \mathrm{~g} / \mathrm{L} \mathrm{MST}(\mathrm{B})$ & 3.8 & $>2.2$ & 1.9 & 3.0 \\
\hline $3 \times 0.2 \mathrm{~g} / \mathrm{L} \mathrm{MST}(\mathrm{H})$ & 1.6 & $>2.2$ & 1.5 & 1.8 \\
\hline $3 \times 0.4 \mathrm{~g} / \mathrm{L}$ MST (E) & 2.1 & $>2.2$ & 2.3 & 3.1 \\
\hline Control $(G)$ & 1.0 & 1.2 & 0.99 & 1.0 \\
\hline
\end{tabular}

\#DFs for $\mathrm{Np}$ were reported for $6 \mathrm{~h}$ instead of $24 \mathrm{~h}$ since the data was all below the detection limit after $6 \mathrm{~h}$. 


\subsubsection{Actual Waste Desorption Testing}

Actual waste desorption tests were conducted to investigate the release of sorbed $\mathrm{Sr}$ and $\mathrm{Pu}$ from loaded MST during washing. Tests used loaded MST from two of the previous Actual Waste MST adsorption tests: Tests A and H (first strike solids only). As with the simulant desorption testing, the use of a centrifuge to concentrate the residual MST solids proved adequate. The target solids concentration and diluted sodium concentrations were obtained with little difficulty. Table 3-11 provides the test characteristics of interest. Specifically, the theoretical maximum $\mathrm{Pu}$ and ${ }^{90} \mathrm{Sr}$ concentrations are well above the analytical detection limit. The concentrations represent the maximum concentrations that would result if all of the species desorbed into the washwater. Examination of the data contained in Table 3-12 shows that ${ }^{90} \mathrm{Sr}$ desorption was minimal (if any) during the $24 \mathrm{~h}$ test period. Desorption of ${ }^{239 / 40} \mathrm{Pu}$ was not detected in the $4,8,12$, or $24 \mathrm{~h}$ samples from either test. Desorption of ${ }^{238} \mathrm{Pu}$ was detected in the 12 and $24 \mathrm{~h}$ samples in both tests, although at concentrations well below the WAC process limits. Less than $0.01 \%$ of the loaded ${ }^{238} \mathrm{Pu}$ desorbed in $24 \mathrm{~h}$. However, the data shows an increasing trend and is insufficient to predict the level of desorption at the end of the cycle time.

Table 3-11 Actual Waste Desorption Test Characteristics

\begin{tabular}{|c|c|c|c|c|c|}
\hline Test ID & $\begin{array}{c}\text { Theoretical } \\
\text { Solids } \\
\text { Concentration } \\
(\mathbf{w t} \%)^{*}\end{array}$ & $\begin{array}{c}\text { Pu } \\
\text { Loading } \\
\text { (umole/g MST) }\end{array}$ & $\begin{array}{c}\text { Theoretical } \\
\text { Max [Pu] } \\
\text { (nCi/g)\# }\end{array}$ & $\begin{array}{c}\text { Sr-90 } \\
\text { Loading } \\
\text { (umole/g MST) }\end{array}$ & $\begin{array}{c}\text { Theoretical } \\
\text { Max [Sr-90] } \\
\text { (nCi/g)\# }\end{array}$ \\
\hline A & 1.9 & 4.3 & 3600 & 0.020 & 560 \\
\hline H & 2.4 & 8.6 & 7200 & 0.054 & 1600 \\
\hline
\end{tabular}

*The theoretical solids concentration is calculated from the mass of MST added to the original adsorption test, the residual volume of test solution from the adsorption test, and the volumes of supernate and wash water added to the desorption test.

\#The theoretical maximum $\mathrm{Pu}$ and ${ }^{90} \mathrm{Sr}$ concentrations represent the maximum concentrations that would result if all of the species desorbed into the washwater.

Table 3-12 Actual Waste Desorption Test Data - Concentration Units of $\mathbf{n C i} / \mathbf{g}$

\begin{tabular}{|c|c|c|c|c|c|c|c|}
\hline \multirow[b]{2}{*}{ Test ID } & \multirow{2}{*}{$\begin{array}{l}\text { Reaction } \\
\text { Time (h) }\end{array}$} & \multicolumn{6}{|c|}{ Concentration (nCi/g) } \\
\hline & & ${ }^{90} \mathrm{Sr}$ & \pm & ${ }^{238} \mathrm{Pu}$ & \pm & ${ }^{239 / 40} \mathrm{Pu}$ & \pm \\
\hline AW-Test A & 0.0 & 0.23 & 0.02 & $<0.101$ & $\mathrm{mda}$ & 0.032 & 0.008 \\
\hline AW-Test A & 4.0 & 0.18 & 0.05 & $<0.036$ & mda & $<0.118$ & mda \\
\hline AW-Test A & 8.0 & $<0.14$ & mda & $<0.574$ & mda & $<0.037$ & mda \\
\hline AW-Test A & 12.0 & $<0.12$ & mda & 0.084 & 0.017 & $<0.153$ & mda \\
\hline AW-Test A & 24.0 & 0.34 & 0.06 & 0.230 & 0.046 & $<0.089$ & mda \\
\hline AW-Test $\mathrm{H}$ & 0.0 & 0.41 & 0.04 & $<2.363$ & $m d a$ & $<0.112$ & $\mathrm{mda}$ \\
\hline AW-Test H & 4.1 & $<0.11$ & mda & $<0.287$ & mda & $<0.068$ & mda \\
\hline AW-Test H & 8.2 & 0.30 & 0.06 & $<0.104$ & mda & $<0.036$ & mda \\
\hline AW-Test H & 12.0 & 0.17 & 0.05 & 0.247 & 0.049 & $<0.054$ & mda \\
\hline AW-Test $\mathrm{H}$ & 24.1 & 0.27 & 0.05 & 0.549 & 0.626 & $<0.064$ & mda \\
\hline & & & & & & & \\
\hline Blank & 4.0 & 0.21 & 0.06 & $<0.035$ & mda & $<0.145$ & mda \\
\hline Blank & 12.0 & 0.14 & 0.05 & 0.065 & 0.013 & $<0.064$ & mda \\
\hline
\end{tabular}

Page 21 


\subsubsection{Mathematical Modeling}

\subsubsection{Prediction of Sorption Performance}

An earlier report determined the Dubinin-Astashov (DA) model best fitted actinide sorption on MST. ${ }^{5}$ That report determined optimal parameters for the Dubinin-Atashov model by regression of a large data set for MST sorption. Personnel used this model to predict actinide loading on MST under the conditions used in this study. To perform the calculations personnel used Jump ${ }^{\oplus}$ software (version 5.03) from the SAS institute.

The authors determined the solute final concentration and the amount of solute loaded on the MST sorbent to assess the sorption prediction. Researchers determined the final solute concentration from the intercept of the operating line and the predicted isotherm (see Figure 3-18). The operating line (OL) represents the mass balance equation between the final and initial solute concentration and the solute loaded on the sorbent. The slope of the operating line is defined as the ratio of solution volume to mass of sorbent. The slope and intercept of the operating line with the predicted isotherm varied with experimental conditions.

Correspondingly, the predicted final solute concentration (i.e., the intercept with the isotherm curve) varied. In the case of several batch additions to a solution, the slope of the operating line decreased with the sequential additions since the ratio of solution volume to solid decreased. The final concentration as determined from the intercept of the OL with DA model decreased. If filtration is conducted between batch additions, the slope of the OL remains the same but the line is offset (shifted) to lower concentrations with each filtration and addition of MST. Consequently, the final actinide concentration decreases even more than for sequential strikes without filtration. The effect of multiple MST strikes and filtration is shown in (The numbers on the operating lines (OL) indicate the order of the MST strike to the solution.) Figure 3-19. With the information above, researchers predicted the final actinide

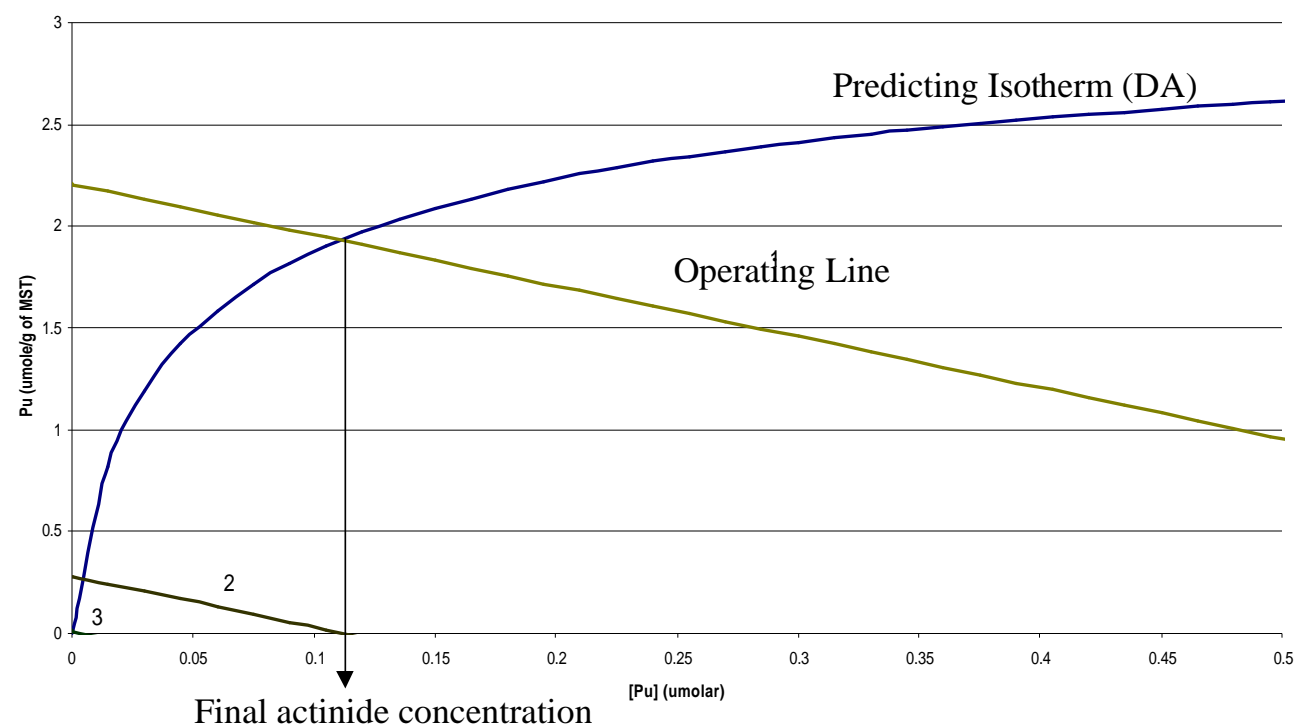

Figure 3-18 The $\mathrm{X}$-value of the intercept of the operating line with the predicting isotherm gives the final concentration for a given batch contact. 


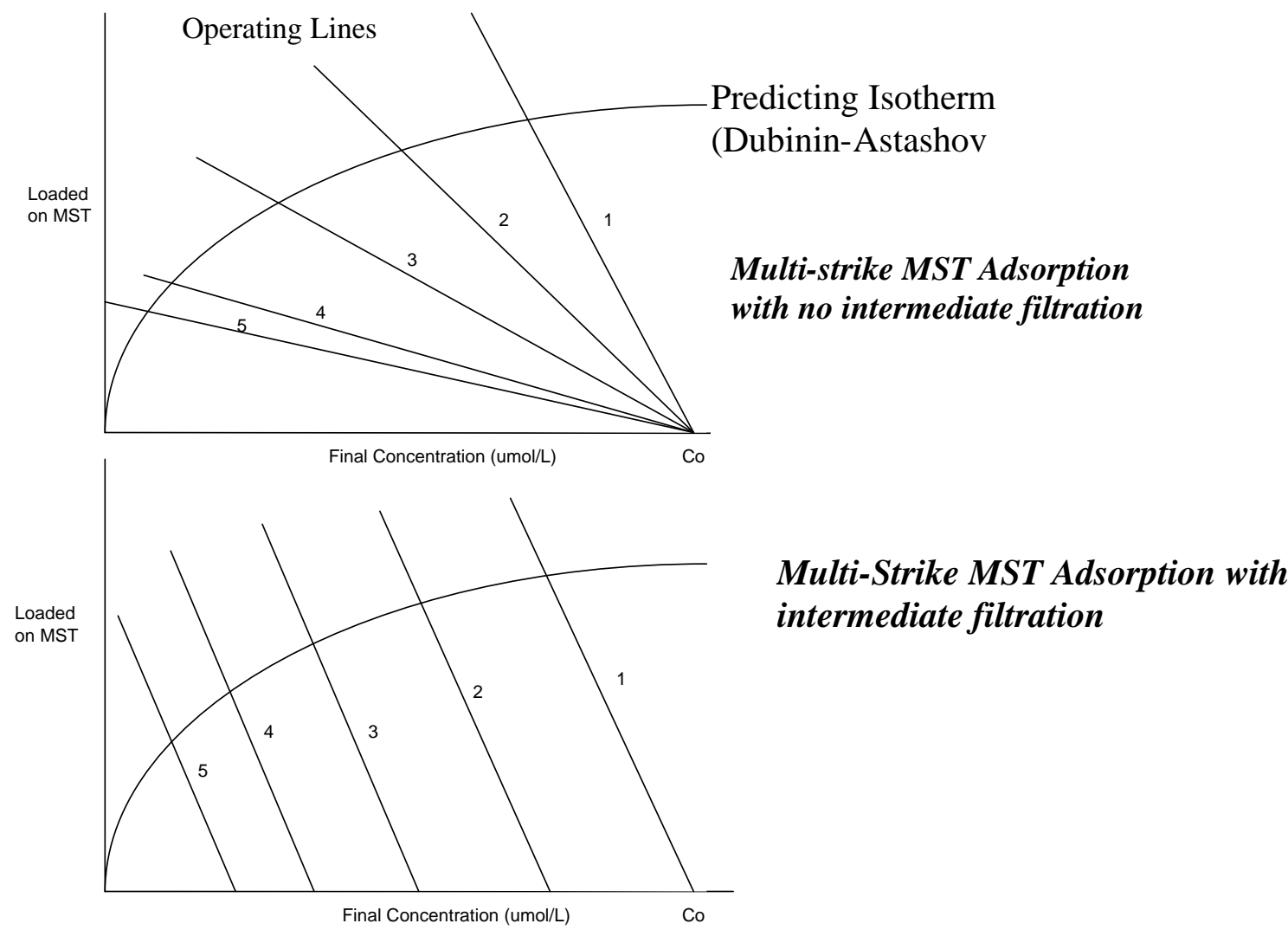

(The numbers on the operating lines (OL) indicate the order of the MST strike to the solution.)

Figure 3-19 The effect of multiple MST strikes and filtration on the final actinide concentration

and $\mathrm{Sr}$ concentrations for the various monosodium titanate addition strategies. The predictions contained errors determined from the individual prediction confidence limits of the isotherm.

Table 3-13 compares the measured versus predicted concentrations of $\mathrm{Sr}$ and actinides for simulant adsorption testing. Table 3-14 compares the measured versus predicted concentrations of $\mathrm{Sr}$ and actinides for actual waste adsorption testing. Examination of the measured versus predicted data shows that, in general, the model over predicts or is close to the measured $\mathrm{Pu}$ concentration and under predicts or is close to the measured $\mathrm{Sr}, \mathrm{Np}$, and $\mathrm{U}$ concentrations. A factor which affects the comparison is that in the case of multiple strikes (with or without filtration), is that the measured values are not at equilibrium (the model is based upon equilibrium data and better predicts data collected after longer times like $168 \mathrm{~h}$, note that equilibrium is assumed to have occurred by $168 \mathrm{~h}$ ). In general, the model does a credible job of predicting the trends in solution concentrations. The model generally appears to offer the best level of predictability for the isotopes with the following order: $\mathrm{Pu}>\mathrm{U}>\mathrm{Sr}$ $>$ Np.

\section{Page 23}


WSRC-TR-2004-00145, REV. 0

Table 3-13 Measured Versus Predicted Solution Concentrations for Simulant Adsorption Tests

\begin{tabular}{|c|c|c|c|c|c|c|c|c|c|c|}
\hline \multirow[b]{2}{*}{ Test ID } & \multirow[b]{2}{*}{$\operatorname{MST}(g / L)$} & \multirow{2}{*}{$\begin{array}{c}\text { Analysis } \\
\text { Time (h)* }\end{array}$} & \multicolumn{2}{|c|}{ Plutonium $(\mu \mathrm{M})$} & \multicolumn{2}{|c|}{ Strontium $(\mu \mathrm{M})$} & \multicolumn{2}{|c|}{ Neptunium $(\mu \mathrm{M})$} & \multicolumn{2}{|c|}{ Uranium $(\mu \mathrm{M})$} \\
\hline & & & Measured & Predicted & Measured & Predicted & Measured & Predicted & Measured & Predicted \\
\hline Test A & 0.4 & 168 & 0.03 & 0.11 & 0.02 & 0.02 & 0.221 & 0.27 & 40 & 32.4 \\
\hline Test B & 0.8 & 168 & 0.02 & 0.02 & 0.012 & 0.008 & 0.08 & $4.00 \mathrm{E}-03$ & 27 & 23 \\
\hline Test $\mathrm{C}$ & 1.2 & 168 & 0.017 & 0.013 & 0.007 & 0.005 & 0.034 & $5.00 \mathrm{E}-05$ & 17 & 16.3 \\
\hline Test D - 1st Strike & $1 \times 0.4$ & $6 \mathrm{~h}$ & 0.129 & 0.110 & 0.026 & 0.020 & 0.94 & 0.27 & 40 & 32.4 \\
\hline Test D - 2nd Strike & $2 \times 0.4$ & $12 \mathrm{~h}$ & 0.045 & 0.025 & 0.012 & 0.008 & 0.32 & $4.00 \mathrm{E}-03$ & 27 & 23 \\
\hline Test D - 3rd Strike & $3 \times 0.4$ & $24 \mathrm{~h}$ & 0.021 & 0.013 & 0.007 & 0.005 & 0.03 & $5.00 \mathrm{E}-05$ & 17 & 16.3 \\
\hline Test D - 3rd Strike & $3 \times 0.4$ & $168 \mathrm{~h}$ & 0.012 & 0.013 & 0.007 & 0.005 & 0.0034 & $5.00 \mathrm{E}-05$ & 16 & 16.3 \\
\hline Test E - 1st Strike & $1 \times 0.4 \mathrm{w} /$ filtration & $6 \mathrm{~h}$ & 0.13 & 0.11 & 0.045 & 0.020 & 0.83 & 0.27 & 40 & 32.4 \\
\hline Test E - 2nd Strike & $2 \times 0.4 \mathrm{w} /$ filtration & $12 \mathrm{~h}$ & 0.014 & 0.005 & 0.0004 & $7.2 \mathrm{E}-5$ & 0.18 & $2.00 \mathrm{E}-13$ & 26 & 20.3 \\
\hline Test E - 3rd Strike & $3 \times 0.4 \mathrm{w} /$ filtration & $24 \mathrm{~h}$ & 0.002 & 0.0005 & 0.0004 & $4.1 \mathrm{E}-7$ & $<0.4$ & $<4 . \mathrm{E}-19$ & 19 & 11.1 \\
\hline Test E - 3rd Strike & $3 \times 0.4 \mathrm{w} /$ filtration & $168 \mathrm{~h}$ & 0.001 & 0.013 & 0.006 & 0.005 & $<0.4$ & $<2 . \mathrm{E}-21$ & 12 & 8 \\
\hline
\end{tabular}

*The analysis time refers to the time at which the measured data was obtained. Correspondingly, all predicted data assume equilibrium was obtained.

Table 3-14 Measured Versus Predicted Solution Concentrations for Actual Waste Adsorption Tests

\begin{tabular}{|c|c|c|c|c|c|c|c|c|c|c|}
\hline \multirow[b]{2}{*}{ Test ID } & \multirow[b]{2}{*}{$\operatorname{MST}(g / L)$} & \multirow{2}{*}{$\begin{array}{c}\text { Analysis } \\
\text { Time (h)* }\end{array}$} & \multicolumn{2}{|c|}{ Plutonium $(\mu \mathrm{M})$} & \multicolumn{2}{|c|}{ Strontium $(\mu \mathrm{M})$} & \multicolumn{2}{|c|}{ Neptunium $(\mu \mathrm{M})$} & \multicolumn{2}{|c|}{ Uranium $(\mu \mathrm{M})$} \\
\hline & & & Measured & Predicted & Measured & Predicted & Measured & Predicted & Measured & Predicted \\
\hline $\mathrm{AW}-$ Test A & 0.4 & 168 & 0.07 & 0.66 & 0.03 & 0.01 & 0.035 & $6.50 \mathrm{E}-07$ & 14.22 & 10.73 \\
\hline AW - Test B & 0.8 & 168 & 0.05 & 0.16 & 0.024 & $3 \mathrm{E}-04$ & 0.024 & $4.00 \mathrm{E}-13$ & 6.9 & 5.33 \\
\hline AW-Test E - 1st Strike & $1 \times 0.4 \mathrm{w} /$ filtration & $6 \mathrm{~h}$ & 0.37 & 0.66 & 0.04 & 0.01 & 0.58 & 0.7 & 14.5 & 11.03 \\
\hline AW-Test E - 2nd Strike & $2 \times 0.4 \mathrm{w} /$ filtration & $12 \mathrm{~h}$ & 0.053 & 0.093 & 0.009 & $3.97 \mathrm{E}-05$ & 0.27 & 0.18 & 9.11 & 4.28 \\
\hline AW-Test E - 3rd Strike & $3 \times 0.4 \mathrm{w} /$ filtration & $24 \mathrm{~h}$ & 0.002 & 0.015 & 0.008 & $2.45 \mathrm{E}-07$ & $<0.24$ & 0.03 & 4.29 & 0.31 \\
\hline AW-Test E - 3rd Strike & $3 \times 0.4 \mathrm{w} /$ filtration & $168 \mathrm{~h}$ & NA & NA & 0.0085 & $2.45 \mathrm{E}-07$ & NA & NA & 1.07 & 0.31 \\
\hline AW-Test H - 1st Strike & $1 \times 0.2 \mathrm{w} /$ filtration & $6 \mathrm{~h}$ & 0.64 & 1.22 & 0.1 & 0.02 & 0.56 & 0.7 & 16.31 & 14.54 \\
\hline AW-Test H - 2nd Strike & $2 \times 0.2 \mathrm{w} /$ filtration & $12 \mathrm{~h}$ & 0.24 & 0.68 & 0.003 & $1.84 \mathrm{E}-04$ & 0.35 & 0.11 & 13.22 & 10.11 \\
\hline AW-Test H - 3rd Strike & $3 \times 0.2 \mathrm{w} /$ filtration & $24 \mathrm{~h}$ & 0.055 & 0.220 & 0.003 & $1.80 \mathrm{E}-06$ & $<0.24$ & 0.012 & $<9.04$ & 6.33 \\
\hline AW-Test H - 3rd Strike & $3 \times 0.2 \mathrm{w} /$ filtration & $168 \mathrm{~h}$ & 0.03 & 0.22 & NA & NA & NA & NA & 6.97 & 6.33 \\
\hline
\end{tabular}

*The analysis time refers to the time at which the measured data was obtained. Correspondingly, all predicted data assume equilibrium was obtained.

\subsection{CONCLUSIONS}

Research over the past decade has studied the adsorption of plutonium and uranium onto MST in alkaline solutions. Tests showed that MST would remove the targeted radionuclides from simulated alkaline waste. Testing indicated that Pu removal kinetics and $\mathrm{Np}$ capacity of the MST material impacts the size of equipment and waste blending plans for the SWPF. Additionally, calculations suggested the baseline MST process (MST concentration of 0.4 $\mathrm{g} / \mathrm{L})$ may not achieve the desired decontamination in wastes containing elevated concentrations of $\mathrm{Pu}$ and $\mathrm{Np}$. In this task, the authors investigated the performance of nonbaseline process parameters and their effectiveness for treating waste feed in the Salt Waste Processing Facility. The work investigated the effect of increased MST addition (up to 1.2 $\mathrm{g} / \mathrm{L}$ ) and the benefit of extra filtration steps with multiple additions of MST to salt waste containing actinides and strontium. Both simulant and actual waste testing were performed. Actual waste tests utilized a Tank $39 \mathrm{H}$ composite waste solution. In addition, testing to determine desorption of actinides from residual MST was conducted. The release of sorbed 
Sr and actinides from loaded MST during the washing stages in the Salt Waste Processing Facility is an unresolved process behavior. Desorption tests were performed to assess this potential problem using loaded MST from the residue of the MST adsorption tests.

Programmatic conclusions drawn from this task follow.

- MST adsorption of Sr and actinides is minimally influenced by multi-strikes (alone) within the $24 \mathrm{~h}$ process cycle time.

- Use of intermediate filtration in conjunction with multiple MST strikes improves removal of $\mathrm{Pu}$ and $\mathrm{Sr}$. The low starting concentration of $\mathrm{Np}$ does not permit determining the influence of intermediate filtration on Np removal.

- The use of intermediate filtration in conjunction with multiple MST strikes is ineffective for increasing $\mathrm{U}$ and Am removal.

- The solubility of Am falls well below Waste Characterization System estimates.

- Desorption of $\mathrm{Sr}$ and $\mathrm{Pu}$ during $24 \mathrm{~h}$ of solids washing does not pose a threat to process limits.

\subsection{FUTURE WORK}

Testing did not identify problematic areas requiring further investigation. However, the authors do recommend further desorption tests to explore desorption from MST well after the $24 \mathrm{~h}$ process time. Furthermore, testing showed that the use of AMP may have influenced the removal of ${ }^{241} \mathrm{Am}$ (possibly caused by a filtration effect). The authors recommend follow-up testing to investigate this observation if AMP is to be continued for use in testing requiring ${ }^{241} \mathrm{Am}$ analysis. Lastly, attempts to analyze non-radioactive $\mathrm{Sr}$ in the tests have proven the current method to be susceptible to higher than acceptable detection limits.

\subsection{ACKNOWLEDGEMENTS}

The authors thank Thomas Peters and Mary Stallings for their assistance in this program. The authors also thank David and C.C. Diprete and Bill Boyce for their analytical support. Technicians providing tremendous assistance in this project included Debra Burckhalter, Mona Blume, and Kim Wyszynski. The authors also thank Gary Dobos who helped design and build the glass actual waste desorption test vessels. Lastly, the authors thank Ron Blessing and Carolyn Conley for their assistance with Shielded Cells activities. 


\subsection{APPENDIX}

Table 7-1 Simulant Adsorption Test Data - Concentration Units of $\mathrm{nCi} / \mathrm{g}$

\begin{tabular}{|c|c|c|c|c|c|c|c|c|c|}
\hline \multirow[b]{2}{*}{ SAMPLE } & \multirow[b]{2}{*}{ TIME (h) } & \multicolumn{8}{|c|}{ Concentration $(\mathrm{nCi} / \mathrm{g})$} \\
\hline & & ${ }^{85} \mathrm{Sr}$ & \pm & $\mathrm{Pu}$ & \pm & ${ }^{237} \mathrm{~Np}$ & \pm & ${ }^{241} \mathrm{Am}$ & \pm \\
\hline Test A & 0 & 74.9 & 1.4 & 12.6 & 0.3 & 0.312 & 0.047 & 2.09 & 0.09 \\
\hline Test A & 6.1 & 1.02 & 0.029 & 1.80 & 0.06 & 0.121 & 0.018 & 0.612 & 0.024 \\
\hline Test A & 12.0 & 0.856 & 0.033 & 1.43 & 0.06 & 0.0926 & 0.0139 & 0.457 & 0.025 \\
\hline Test $\mathrm{A}$ & 24.0 & 0.748 & 0.024 & 1.00 & 0.05 & 0.0579 & 0.0087 & 0.288 & 0.015 \\
\hline Test A & 48.0 & 0.735 & 0.029 & 0.756 & 0.052 & 0.0458 & 0.0069 & 0.215 & 0.015 \\
\hline Test A & 168 & 0.590 & 0.015 & 0.428 & 0.057 & 0.0302 & 0.0045 & 0.147 & 0.005 \\
\hline Test B & 0.0 & 75.2 & 1.4 & 12.8 & 0.3 & 0.324 & 0.049 & 2.00 & 0.08 \\
\hline Test B & 6.1 & 0.376 & 0.016 & 0.859 & 0.050 & 0.0513 & 0.0077 & 0.520 & 0.021 \\
\hline Test B & 12.0 & 0.324 & 0.019 & 0.646 & 0.046 & 0.0402 & 0.0060 & 0.406 & 0.020 \\
\hline Test B & 24.0 & 0.307 & 0.014 & 0.503 & 0.036 & 0.0290 & 0.0043 & 0.247 & 0.012 \\
\hline Test B & 48.0 & 0.241 & 0.017 & 0.353 & 0.025 & 0.0171 & 0.0026 & 0.176 & 0.013 \\
\hline Test B & 168 & 0.267 & 0.007 & 0.253 & 0.041 & 0.0107 & 0.0016 & 0.109 & 0.005 \\
\hline Test C1 & 0.0 & 74.2 & 1.4 & 12.4 & 0.3 & 0.339 & 0.051 & 2.09 & 0.09 \\
\hline Test C1 & 6.2 & 0.202 & 0.012 & 0.630 & 0.039 & 0.0431 & 0.0065 & 0.480 & 0.020 \\
\hline Test $\mathrm{C} 1$ & 12.1 & 0.191 & 0.014 & 0.523 & 0.038 & 0.0254 & 0.0038 & 0.338 & 0.020 \\
\hline Test C1 & 24.0 & 0.185 & 0.012 & 0.285 & 0.038 & 0.0128 & 0.0019 & 0.248 & 0.012 \\
\hline Test C1 & 48.0 & 0.174 & 0.014 & 0.379 & 0.043 & 0.0083 & 0.0012 & 0.155 & 0.012 \\
\hline Test C1 & 168 & 0.157 & 0.006 & 0.299 & 0.064 & $<0.0046$ & mda & 0.108 & 0.004 \\
\hline Test C2 & 0.0 & 76.4 & 1.5 & 12.5 & 0.3 & 0.329 & 0.049 & 2.17 & 0.09 \\
\hline Test C2 & 6.2 & 0.230 & 0.012 & 0.565 & 0.034 & 0.0479 & 0.0072 & 0.473 & 0.019 \\
\hline Test C2 & 12.2 & 0.203 & 0.015 & 0.418 & 0.033 & 0.0208 & 0.0031 & 0.348 & 0.019 \\
\hline Test C2 & 24.0 & 0.181 & 0.012 & 0.279 & 0.055 & 0.0133 & 0.0020 & 0.221 & 0.012 \\
\hline Test C2 & 48.1 & 0.200 & 0.015 & 0.270 & 0.022 & 0.0103 & 0.0015 & 0.163 & 0.012 \\
\hline Test C2 & 168 & 0.152 & 0.006 & 0.191 & 0.042 & $<0.0046$ & mda & 0.097 & 0.004 \\
\hline Test D & 0.0 & 76.3 & 1.5 & 12.9 & 0.3 & 0.330 & 0.050 & 2.19 & 0.08 \\
\hline Test D & 6.2 & 0.974 & 0.029 & 1.87 & 0.08 & 0.128 & 0.019 & 0.630 & 0.024 \\
\hline Test D & 12.1 & 0.341 & 0.019 & 0.651 & 0.045 & 0.0435 & 0.0065 & 0.404 & 0.020 \\
\hline Test D & 24.0 & 0.164 & 0.010 & 0.300 & 0.072 & 0.0160 & 0.0024 & 0.239 & 0.012 \\
\hline Test D & 35.9 & 0.167 & 0.015 & 0.257 & 0.024 & 0.0089 & 0.0013 & 0.185 & 0.014 \\
\hline Test D & 48.1 & 0.183 & 0.013 & 0.231 & 0.030 & 0.0077 & 0.0012 & 0.198 & 0.018 \\
\hline Test D & 168 & 0.148 & 0.007 & 0.174 & 0.027 & $<0.0046$ & mda & 0.098 & 0.004 \\
\hline Test E1 & 0.0 & 75.0 & 1.4 & 12.5 & 0.3 & 0.322 & 0.048 & 2.14 & 0.09 \\
\hline Test E1 & 6.3 & 0.967 & 0.028 & 1.90 & 0.06 & 0.113 & 0.017 & 0.629 & 0.024 \\
\hline Test E1 & 12.3 & $<0.009$ & mda & 0.208 & 0.014 & 0.0247 & 0.0037 & 0.422 & 0.012 \\
\hline Test E1 & 24.0 & $<0.009$ & mda & 0.028 & 0.004 & $<0.0060$ & mda & 0.284 & 0.009 \\
\hline Test E1 & 35.9 & $<0.008$ & mda & 0.019 & 0.003 & $<0.0060$ & mda & 0.243 & 0.008 \\
\hline Test E1 & 48.1 & $<0.008$ & mda & 0.024 & 0.005 & $<0.0046$ & mda & 0.198 & 0.007 \\
\hline Test E1 & 168 & $<0.009$ & mda & 0.012 & 0.002 & $<0.0046$ & mda & 0.111 & 0.004 \\
\hline Test E2 & 0.0 & 75.3 & 1.4 & 12.5 & 0.3 & 0.332 & 0.050 & 2.00 & 0.10 \\
\hline Test E2 & 6.3 & 0.956 & 0.028 & 1.75 & 0.06 & 0.124 & 0.019 & 0.596 & 0.025 \\
\hline Test E2 & 12.3 & $<0.009$ & mda & 0.185 & 0.011 & 0.0246 & 0.0037 & 0.428 & 0.013 \\
\hline Test E2 & 24.1 & $<0.008$ & mda & 0.032 & 0.004 & $<0.0060$ & mda & 0.260 & 0.008 \\
\hline Test E2 & 35.9 & $<0.008$ & $\mathrm{mda}$ & 0.040 & 0.005 & $<0.0060$ & mda & 0.216 & 0.007 \\
\hline Test E2 & 48.1 & $<0.009$ & mda & 0.013 & 0.002 & $<0.0046$ & mda & 0.185 & 0.006 \\
\hline Test E2 & 168 & $<0.009$ & mda & 0.011 & 0.002 & $<0.0046$ & mda & 0.109 & 0.004 \\
\hline Test F & 0.0 & 75.3 & 1.4 & 12.4 & 0.3 & 0.307 & 0.046 & 2.19 & 0.09 \\
\hline Test F & 6.3 & 77.2 & 1.5 & 12.7 & 0.4 & 0.304 & 0.046 & 2.02 & 0.08 \\
\hline Test $\mathrm{F}$ & 12.3 & 76.6 & 1.5 & 13.1 & 0.3 & 0.275 & 0.041 & 2.02 & 0.08 \\
\hline Test F & 24.1 & 74.5 & 1.4 & 12.1 & 0.3 & 0.229 & 0.034 & 1.73 & 0.08 \\
\hline Test $\mathrm{F}$ & 36.0 & 73.4 & 1.4 & 12.1 & 0.3 & 0.264 & 0.040 & 1.56 & 0.08 \\
\hline Test $\mathrm{F}$ & 48.1 & 74.9 & 1.4 & 12.7 & 0.4 & 0.292 & 0.044 & 1.43 & 0.07 \\
\hline Test F & 168 & 76.5 & 1.4 & 12.5 & 0.3 & 0.284 & 0.043 & 1.18 & 0.04 \\
\hline
\end{tabular}


Table 7-2 Simulant Adsorption Test Data - Concentration Units of $\mu \mathrm{g} / \mathrm{L}$

\begin{tabular}{|c|c|c|c|c|c|c|c|c|c|c|c|}
\hline \multirow[b]{2}{*}{ SAMPLE } & \multirow[b]{2}{*}{ TIME (h) } & \multicolumn{10}{|c|}{ Concentration $(\mu \mathrm{g} / \mathrm{L})$} \\
\hline & & ${ }^{85} \mathrm{Sr}$ & \pm & $\mathbf{P u}$ & \pm & ${ }^{237} \mathrm{~Np}$ & \pm & $\mathbf{U}$ & \pm & ${ }^{241} \mathrm{Am}$ & \pm \\
\hline Test A & 0 & $3.89 E-03$ & 7.4E-05 & 212 & 5 & 540 & 81 & 11400 & 1720 & 0.745 & 0.034 \\
\hline Test A & 6.1 & 5.31E-05 & $1.5 \mathrm{E}-06$ & 30.0 & 0.9 & 210 & 32 & 9360 & 1400 & 0.218 & 0.009 \\
\hline Test A & 12.0 & 4.44E-05 & 1.7E-06 & 23.6 & 0.9 & 160 & 24 & 8220 & 1230 & 0.163 & 0.009 \\
\hline Test A & 24.0 & 3.88E-05 & 1.3E-06 & 16.8 & 0.7 & 100 & 15 & 7000 & 1050 & 0.103 & 0.005 \\
\hline Test A & 48.0 & 3.81E-05 & $1.5 \mathrm{E}-06$ & 12.6 & 0.8 & 79.4 & 11.9 & 7200 & 1080 & 0.0767 & 0.0052 \\
\hline Test A & 168 & $3.06 \mathrm{E}-05$ & 7.6E-07 & 7.1 & 0.9 & 52.4 & 7.9 & 6240 & 936 & 0.0525 & 0.0019 \\
\hline Test B & 00 & $390 \mathrm{~F}-03$ & $74 \mathrm{E}-05$ & 214 & 6 & 562 & 84 & 11600 & 1750 & 0714 & 0029 \\
\hline Test B & 6.1 & $1.95 \mathrm{E}-05$ & 8.3E-07 & 14.2 & 0.7 & 89.0 & 13.3 & 6270 & 940 & 0.185 & 0.007 \\
\hline Test B & 12.0 & 1.68E-05 & 1.0E-06 & 10.3 & 0.7 & 69.6 & 10.4 & 6370 & 955 & 0.145 & 0.007 \\
\hline Test B & 24.0 & $1.59 \mathrm{E}-05$ & 7.5E-07 & 7.9 & 0.5 & 50.2 & 7.5 & 5370 & 806 & 0.0881 & 0.0044 \\
\hline Test B & 48.0 & $1.25 \mathrm{E}-05$ & 9.0E-07 & 6.0 & 0.3 & 29.6 & 4.4 & 4670 & 700 & 0.0628 & 0.0045 \\
\hline Test B & 168 & 1.38E-05 & 3.9E-07 & 4.1 & 0.6 & 18.6 & 2.8 & 4050 & 607 & 0.0388 & 0.0017 \\
\hline & & & & & & & & & & & \\
\hline Test C1 & 0.0 & $3.85 E-03$ & $7.3 E-05$ & 207 & 5 & 588 & 88 & 12100 & 1820 & 0.745 & 0.034 \\
\hline Test C1 & 6.2 & $1.05 \mathrm{E}-05$ & 6.3E-07 & 10.2 & 0.5 & 74.7 & 11.2 & 5660 & 848 & 0.171 & 0.007 \\
\hline Test $\mathrm{C} 1$ & 12.1 & 9.89E-06 & 7.3E-07 & 8.7 & 0.6 & 44.1 & 6.6 & 4880 & 732 & 0.120 & 0.007 \\
\hline Test $\mathrm{C} 1$ & 24.0 & 9.58E-06 & $6.4 \mathrm{E}-07$ & 4.8 & 0.6 & 22.3 & 3.3 & 3930 & 589 & 0.0884 & 0.0044 \\
\hline Test $\mathrm{C} 1$ & 48.0 & $9.01 E-06$ & 7.3E-07 & 6.3 & 0.7 & 14.4 & 2.2 & 3350 & 502 & 0.0551 & 0.0042 \\
\hline Test C1 & 168 & $8.15 E-06$ & $3.1 \mathrm{E}-07$ & 4.8 & 0.9 & 8.0 & 1.2 & 1630 & 244 & 0.0386 & 0.0015 \\
\hline Test C2 & 0.0 & $3.96 \mathrm{E}-03$ & $7.6 \mathrm{E}-05$ & 209 & 5 & 570 & 86 & 11700 & 1760 & 0.772 & 0.033 \\
\hline Test C2 & 6.2 & 1.19E-05 & 6.4E-07 & 9.2 & 0.5 & 83.0 & 12.5 & 6110 & 916 & 0.168 & 0.007 \\
\hline Test C2 & 12.2 & $1.05 E-05$ & 7.6E-07 & 7.0 & 0.5 & 36.1 & 5.4 & 4880 & 732 & 0.124 & 0.007 \\
\hline Test C2 & 24.0 & 9.37E-06 & $6.1 \mathrm{E}-07$ & 4.6 & 0.9 & 23.0 & 3.5 & 3750 & 563 & 0.0788 & 0.0041 \\
\hline Test C2 & 48.1 & $1.04 \mathrm{E}-05$ & 7.8E-07 & 4.4 & 0.3 & 17.8 & 2.7 & 2740 & 411 & 0.0579 & 0.0044 \\
\hline Test C2 & 168 & 7.88E-06 & 3.1E-07 & 3.1 & 0.7 & 8.0 & 1.2 & 3740 & 562 & 0.0346 & 0.0016 \\
\hline Test D & 0.0 & $3.96 \mathrm{E}-03$ & $7.6 \mathrm{E}-05$ & 216 & 6 & 572 & 86 & 11600 & 1730 & 0.781 & 0.030 \\
\hline Test D & 6.2 & 5.05E-05 & $1.5 \mathrm{E}-06$ & 30.9 & 1.2 & 222 & 33 & 9490 & 1420 & 0.224 & 0.009 \\
\hline Test D & 12.1 & 1.77E-05 & $9.9 \mathrm{E}-07$ & 10.9 & 0.7 & 75.5 & 11.3 & 6420 & 964 & 0.144 & 0.007 \\
\hline Test D & 24.0 & 8.48E-06 & 5.3E-07 & 4.9 & 1.2 & 27.8 & 4.2 & 4100 & 616 & 0.0851 & 0.0044 \\
\hline Test D & 35.9 & 8.67E-06 & 7.8E-07 & 4.4 & 0.4 & 15.5 & 2.3 & 3720 & 559 & 0.0660 & 0.0049 \\
\hline Test D & 48.1 & $9.48 E-06$ & $6.8 \mathrm{E}-07$ & 3.9 & 0.5 & 13.4 & 2.0 & 3340 & 500 & 0.0704 & 0.0064 \\
\hline Test D & 168 & $7.65 \mathrm{E}-06$ & 3.4E-07 & 2.9 & 0.4 & 8.0 & 1.2 & 2320 & 348 & 0.0349 & 0.0014 \\
\hline Test E1 & 0.0 & 3.89E-03 & 7.4E-05 & 209 & 5 & 558 & 84 & 11500 & 1730 & 0.763 & 0.031 \\
\hline Test E1 & 6.3 & 5.02E-05 & 1.5E-06 & 31.0 & 1.0 & 196 & 29 & 9480 & 1420 & 0.224 & 0.009 \\
\hline Test E1 & 12.3 & $<4.5 \mathrm{E}-07$ & mda & 3.5 & 0.2 & 42.8 & 6.4 & 6940 & 1040 & 0.151 & 0.004 \\
\hline Test E1 & 24.0 & $<4.4 \mathrm{E}-07$ & mda & 0.45 & 0.06 & 10.4 & 1.6 & 4570 & 686 & 0.101 & 0.003 \\
\hline Test E1 & 35.9 & $<4.4 \mathrm{E}-07$ & mda & 0.31 & 0.05 & 10.4 & 1.6 & 4860 & 729 & 0.0864 & 0.0028 \\
\hline Test E1 & 48.1 & $<4.2 \mathrm{E}-07$ & mda & 0.40 & 0.08 & 8.0 & 1.2 & 4040 & 607 & 0.0704 & 0.0025 \\
\hline Test E1 & 168 & $<4.9 \mathrm{E}-07$ & mda & 0.19 & 0.03 & 8.0 & 1.2 & 2100 & 315 & 0.0395 & 0.0015 \\
\hline & & & & & & & & & & & \\
\hline Test E2 & 0.0 & 3.91E-03 & $7.5 \mathrm{E}-05$ & 209 & 6 & 576 & 86 & 12000 & 1800 & 0.714 & 0.035 \\
\hline Test E2 & 6.3 & 4.96E-05 & 1.5E-06 & 29.1 & 1.0 & 215 & 32 & 9600 & 1440 & 0.213 & 0.009 \\
\hline Test E2 & 12.3 & $<4.6 \mathrm{E}-07$ & mda & 3.1 & 0.2 & 42.6 & 6.4 & 5610 & 842 & 0.152 & 0.005 \\
\hline Test E2 & 24.1 & $<4.2 \mathrm{E}-07$ & mda & 0.48 & 0.05 & 10.4 & 1.6 & 4640 & 696 & 0.0925 & 0.0030 \\
\hline Test E2 & 35.9 & $<4.4 \mathrm{E}-07$ & mda & 0.37 & 0.04 & 10.4 & 1.6 & 4270 & 641 & 0.0770 & 0.0023 \\
\hline Test E2 & 48.1 & $<4.5 \mathrm{E}-07$ & mda & 0.20 & 0.02 & 8.0 & 1.2 & 4310 & 647 & 0.0659 & 0.0022 \\
\hline Test E2 & 168 & $<4.8 \mathrm{E}-07$ & mda & 0.17 & 0.04 & 8.0 & 1.2 & 3710 & 556 & 0.0389 & 0.0015 \\
\hline Test F & 0.0 & $3.90 \mathrm{E}-03$ & $7.5 \mathrm{E}-05$ & 208 & 6 & 532 & 80 & 11200 & 1680 & 0.782 & 0.033 \\
\hline Test $\mathrm{F}$ & 6.3 & $4.00 \mathrm{E}-03$ & 7.6E-05 & 213 & 6 & 528 & 79 & 11700 & 1750 & 0.721 & 0.030 \\
\hline Test F & 12.3 & 3.97E-03 & 7.6E-05 & 220 & 6 & 476 & 71 & 10200 & 1540 & 0.719 & 0.030 \\
\hline Test F & 24.1 & $3.86 \mathrm{E}-03$ & 7.3E-05 & 204 & 6 & 397 & 60 & 8410 & 1260 & 0.617 & 0.027 \\
\hline Test F & 36.0 & 3.80E-03 & 7.3E-05 & 203 & 5 & 458 & 69 & 9700 & 1460 & 0.557 & 0.028 \\
\hline Test $\mathrm{F}$ & 48.1 & 3.88E-03 & 7.5E-05 & 213 & 6 & 507 & 76 & 10300 & 1540 & 0.509 & 0.025 \\
\hline Test F & 168 & 3.97E-03 & 7.5E-05 & 211 & 5 & 492 & 74 & 10700 & 1600 & 0.422 & 0.015 \\
\hline
\end{tabular}


WSRC-TR-2004-00145, REV. 0

Table 7-3 Actual Waste Adsorption Test Data - Concentration Units of $\mathbf{n C i} / \mathbf{g}$

\begin{tabular}{|c|c|c|c|c|c|c|c|c|c|c|c|c|c|}
\hline \multirow[b]{2}{*}{ SAMPLE } & \multirow[b]{2}{*}{ TIME (h) } & \multicolumn{12}{|c|}{ Concentration (nCi/g) } \\
\hline & & ${ }^{90} \mathrm{Sr}$ & \pm & ${ }^{238} \mathrm{Pu}$ & \pm & ${ }^{239 / 40} \mathrm{Pu}$ & \pm & Total Pu & \pm & ${ }^{237} \mathrm{~Np}$ & \pm & ${ }^{241} \mathrm{Am}$ & \pm \\
\hline AW-Test A & 0.0 & 79.2 & 7.9 & 479 & 20 & 24.7 & 1.3 & 504 & 21 & 0.0770 & 0.0192 & $<0.034$ & $\overline{m d a}$ \\
\hline AW-Test A & 6.1 & 1.49 & 0.16 & 103 & 3 & 5.3 & 0.2 & 108 & 3 & 0.0368 & 0.0092 & $<0.030$ & $\mathrm{mda}$ \\
\hline AW-Test A & 12.0 & 1.56 & 0.17 & 87.0 & 2.4 & 4.5 & 0.2 & 91.5 & 2.6 & $<0.032$ & mda & $<0.039$ & mda \\
\hline AW-Test A & 24.0 & 1.43 & 0.17 & 64.9 & 1.8 & 3.1 & 0.1 & 68.0 & 1.9 & $<0.027$ & mda & $<0.029$ & mda \\
\hline AW-Test A & 168 & 1.47 & 0.14 & 18.8 & 0.5 & 1.0 & 0.0 & 19.8 & 0.5 & $<0.036$ & mda & $<0.036$ & $\mathrm{mda}$ \\
\hline & & & & & & & & & & & & & \\
\hline AW-Test B & 0.0 & 83.5 & 8.4 & 503 & 17 & 26.7 & 1.0 & 530 & 18 & 0.0753 & 0.0188 & $<0.030$ & mda \\
\hline AW-Test B & 6.0 & 1.60 & 0.18 & 50.5 & 1.3 & 2.5 & 0.1 & 53.0 & 1.4 & 0.0198 & 0.0049 & $<0.036$ & mda \\
\hline AW-Test B & 11.9 & 0.92 & 0.11 & 42.3 & 1.1 & 2.2 & 0.1 & 44.5 & 1.2 & $<0.032$ & mda & $<0.035$ & mda \\
\hline AW-Test B & 24.0 & 0.86 & 0.11 & 33.0 & 0.9 & 1.8 & 0.1 & 34.8 & 1.0 & $<0.026$ & mda & $<0.028$ & mda \\
\hline AW-Test B & 168 & 1.01 & 0.10 & 12.4 & 0.3 & 0.7 & 0.0 & 13.0 & 0.4 & $<0.034$ & mda & $<0.035$ & mda \\
\hline AW-Test E & 0.0 & 88.0 & 8.8 & 480 & 15 & 24.8 & 0.9 & 505 & 16 & 0.0772 & 0.0193 & $<0.035$ & $\mathrm{mda}$ \\
\hline AW-Test E & 6.2 & 1.68 & 0.21 & 103 & 3 & 5.3 & 0.2 & 108 & 3 & 0.0361 & 0.0090 & $<0.032$ & mda \\
\hline AW-Test E & 11.9 & 0.39 & 0.09 & 26.6 & 0.7 & 1.3 & 0.1 & 27.9 & 0.8 & $<0.032$ & mda & $<0.032$ & mda \\
\hline AW-Test E & 24.0 & 0.34 & 0.08 & 4.0 & 0.1 & 0.2 & 0.0 & 4.2 & 0.1 & $<0.027$ & mda & $<0.028$ & mda \\
\hline AW-Test E & 168 & 0.37 & 0.05 & 1.9 & 0.1 & 0.1 & 0.0 & 2.0 & 0.1 & $<0.036$ & mda & $<0.050$ & mda \\
\hline AW-7 & 00 & 725 & 73 & 399 & & 21 & & & & 00789 & 00107 & & $m d a$ \\
\hline AW-Test G & 5.9 & 102 & 10 & 485 & 13 & 25 & 1 & 419 & 14 & 0.0767 & 0.0197 & $<0.032$ & mda \\
\hline AW-Test G & 11.9 & 126 & 10 & 472 & 15 & 24 & 1 & 496 & $\begin{array}{l}14 \\
16\end{array}$ & $<0.033$ & mda & $<0.042$ & mda \\
\hline AW-Test G & 24.0 & 91.0 & 9.1 & 481 & 15 & 24 & 1 & 505 & 16 & 0.0963 & 0.0241 & $<0.032$ & $\mathrm{mda}$ \\
\hline AW-Test G & 168 & 91.2 & 7.4 & 494 & 14 & 25 & 1 & 520 & 15 & 0.0677 & 0.0169 & $<0.044$ & mda \\
\hline & & & & & & & & & & & & & \\
\hline AW-Test H & 0.0 & 111 & 11 & 470 & 20 & 25.7 & 1.3 & 496 & 21 & 0.0750 & 0.0188 & $<0.054$ & mda \\
\hline AW-Test H & 6.3 & 5.27 & 0.54 & 181 & 5 & 9.2 & 0.3 & 190 & 5 & 0.0469 & 0.0117 & $<0.029$ & mda \\
\hline AW-Test H & 11.9 & 0.17 & 0.06 & 68.1 & 1.8 & 3.5 & 0.1 & 71.6 & 1.9 & $<0.032$ & mda & $<0.030$ & mda \\
\hline AW-Test H & 24.1 & 0.17 & 0.05 & 16.0 & 0.4 & 0.8 & 0.1 & 16.8 & 0.5 & $<0.029$ & mda & $<0.035$ & mda \\
\hline AW-Test H & 168 & 0.18 & 0.03 & 6.0 & 0.2 & 0.4 & 0.0 & 6.3 & 0.2 & $<0.035$ & mda & $<0.030$ & mda \\
\hline Blank & 00 & 015 & 005 & 028 & 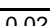 & $<017$ & mda & -046 & & $<0003$ & & 80028 & $\mathrm{mda}$ \\
\hline Blank & 5.9 & 0.77 & 0.11 & 0.30 & 0.03 & $<0.34$ & mda & $<0.64$ & mda & $<0.003$ & mda & $<0.027$ & mda \\
\hline Blank & 12.0 & 0.20 & 0.05 & $<0.02$ & mda & $<0.05$ & mda & $<0.07$ & mda & $<0.032$ & mda & $<0.033$ & mda \\
\hline Blank & 24.1 & 0.31 & 0.07 & 0.56 & 0.04 & $<0.29$ & mda & $<0.84$ & mda & $<0.026$ & mda & $<0.044$ & mda \\
\hline Blank & 168 & 0.24 & 0.05 & $<0.02$ & mda & 0.02 & 0.01 & $<0.03$ & mda & $<0.034$ & mda & $<0.028$ & mda \\
\hline
\end{tabular}

Table 7-4 Actual Waste Adsorption Test Data - Concentration Units of $\mu \mathrm{g} / \mathrm{L}$

\begin{tabular}{|c|c|c|c|c|c|c|c|c|c|c|c|c|c|c|c|}
\hline \multirow[b]{2}{*}{ SAMPLE } & \multirow[b]{2}{*}{ TIME (h) } & \multicolumn{14}{|c|}{ Concentration $(\mu \mathrm{g} / \mathrm{L})$} \\
\hline & & ${ }^{90} \mathrm{Sr}$ & \pm & ${ }^{238} \mathrm{Pu}$ & \pm & ${ }^{239 / 40} \mathrm{Pu}$ & \pm & Total Pu & \pm & ${ }^{237} \mathrm{~Np}$ & \pm & U & \pm & ${ }^{241} \mathrm{Am}$ & \pm \\
\hline AW-Test A & 0.0 & 0.721 & 0.072 & 35.0 & 1.4 & 380 & 20 & 415 & 21 & 136 & 34 & 4690 & 703 & $<0.012$ & mda \\
\hline AW-Test A & 6.1 & 0.0136 & 0.0014 & 7.49 & 0.19 & 81.5 & 2.5 & 89.0 & 2.7 & 65.1 & 16.3 & 3860 & 579 & $<0.011$ & mda \\
\hline AW-Test A & 12.0 & 0.0142 & 0.0015 & 6.35 & 0.17 & 68.8 & 3.7 & 75.2 & 3.9 & $<56$ & $\mathrm{mda}$ & 3470 & 520 & $<0.014$ & mda \\
\hline AW-Test A & 24.0 & 0.0130 & 0.0016 & 4.73 & 0.13 & 48.4 & 2.1 & 53.1 & 2.2 & $<47$ & mda & 3510 & 527 & $<0.011$ & mda \\
\hline AW-Test A & 168 & 0.0134 & 0.0013 & 1.37 & 0.04 & 15.4 & 0.7 & 16.8 & 0.8 & $<64$ & mda & 2970 & 446 & $<0.013$ & mda \\
\hline & & & & & & & & & & & & & & & \\
\hline AW-Test B & 0.0 & 0.761 & 0.076 & 36.7 & 1.3 & 411 & 16 & 447 & 17 & 133 & 33 & 4660 & 699 & $<0.011$ & mda \\
\hline AW-Test B & 6.0 & 0.0146 & 0.0017 & 3.68 & 0.09 & 39.2 & 1.5 & 42.8 & 1.6 & 35.0 & 8.8 & 3080 & 461 & $<0.013$ & mda \\
\hline AW-Test B & 11.9 & 0.0084 & 0.0010 & 3.09 & 0.08 & 33.2 & 1.6 & 36.3 & 1.7 & $<57$ & mda & 2440 & 366 & $<0.013$ & mda \\
\hline AW-Test B & 24.0 & 0.0078 & 0.0010 & 2.41 & 0.06 & 28.1 & 1.3 & 30.5 & 1.3 & $<46$ & mda & 2430 & 365 & $<0.010$ & mda \\
\hline AW-Test B & 168 & 0.0092 & 0.0009 & 0.90 & 0.02 & 10.2 & 0.5 & 11.1 & 0.5 & $<60$ & $\mathrm{mda}$ & 1630 & 245 & $<0.013$ & mda \\
\hline AW-Test F & 00 & 0802 & מקח & 350 & & 381 & & 417 & 15 & & 34 & 4780 & & -0013 & $m d a$ \\
\hline $\begin{array}{l}\text { AVW-Iest } \\
\text { AW-Test }\end{array}$ & $\begin{array}{l}0.0 \\
6.2\end{array}$ & 0.802 & 0.080 & $\begin{array}{l}35.0 \\
750\end{array}$ & $\begin{array}{l}1.1 \\
0.20\end{array}$ & $\begin{array}{l}381 \\
821\end{array}$ & $\begin{array}{l}14 \\
24\end{array}$ & 417 & 15 & 137 & 34 & $\begin{array}{l}4780 \\
3680\end{array}$ & $\begin{array}{l}717 \\
552\end{array}$ & $<0.013$ & mda \\
\hline AW-Test E & 11.9 & 0.0035 & 0.0008 & 1.94 & 0.05 & 20.4 & 1.2 & 22.3 & 1.2 & $<56$ & mda & 2830 & 424 & $<0.012$ & mda \\
\hline AW-Test E & 24.0 & 0.0031 & 0.0007 & 0.29 & 0.01 & 3.23 & 0.39 & 3.52 & 0.40 & $<48$ & mda & 2140 & 321 & $<0.010$ & mda \\
\hline AW-Test E & 168 & 0.0034 & 0.0005 & 0.14 & 0.01 & 1.17 & 0.23 & 1.30 & 0.24 & $<64$ & mda & 1640 & 247 & $<0.018$ & mda \\
\hline & & & & & & & & & & & & & & & \\
\hline AW-Test G & 0.0 & 0.661 & 0.066 & 29.1 & 0.9 & 316 & 11 & 345 & 12 & 140 & 35 & 4670 & 700 & $<0.012$ & mda \\
\hline AW-Test G & 5.9 & 0.934 & 0.090 & 35.4 & 1.0 & 379 & 11 & 414 & 12 & 136 & 34 & 4700 & 704 & $<0.012$ & mda \\
\hline AW-Test G & 11.9 & 1.15 & 0.09 & 34.4 & 1.1 & 372 & 13 & 407 & 14 & $<58$ & mda & 1260 & 189 & $<0.015$ & mda \\
\hline AW-Test G & 24.0 & 0.829 & 0.083 & 35.1 & 1.1 & 366 & 14 & 401 & 15 & 171 & 43 & 4820 & 723 & $<0.012$ & mda \\
\hline AW-Test G & 168 & 0.831 & 0.067 & 36.1 & 1.0 & 392 & 12 & 428 & 13 & 120 & 30 & 4550 & 683 & $<0.016$ & mda \\
\hline AW-Test H & 00 & 101 & 0.10 & 343 & 14 & 395 & 20 & & 21 & & & 4660 & 699 & & \\
\hline AW-Test H & 6.3 & 0.0480 & 0.0049 & 13.2 & 0.3 & 141 & 4 & 154 & 4 & 83.1 & 20.8 & $\begin{array}{l}4060 \\
4060\end{array}$ & 610 & $<0.010$ & mda \\
\hline AW-Test $\mathrm{H}$ & 11.9 & 0.0015 & 0.0005 & 4.97 & 0.13 & 53.4 & 2.0 & 58.4 & 2.1 & $<57$ & mda & 3540 & 531 & $<0.011$ & mda \\
\hline AW-Test $\mathrm{H}$ & 24.1 & 0.0015 & 0.0005 & 1.17 & 0.03 & 12.0 & 0.8 & 13.2 & 0.9 & $<51$ & mda & 3230 & 485 & $<0.013$ & mda \\
\hline AW-Test $\mathrm{H}$ & 168 & 0.0017 & 0.0003 & 0.43 & 0.01 & 5.88 & 0.41 & 6.3 & 0.4 & $<61$ & mda & 2550 & 382 & $<0.011$ & mda \\
\hline & & & & & & & & & & & & & & & \\
\hline Blank & 0.0 & 0.0013 & 0.0004 & 0.0207 & 0.0017 & $<2.69$ & mda & $<2.71$ & $\mathrm{DL}$ & $<4.7$ & mda & $<19$ & mda & $<0.010$ & mda \\
\hline Blank & 5.9 & 0.0070 & 0.0010 & 0.0218 & 0.0020 & $<5.20$ & $\mathrm{mda}$ & $<5.22$ & $\mathrm{DL}$ & $<4.6$ & mda & $<22$ & mda & $<0.010$ & mda \\
\hline Blank & 12.0 & 0.0018 & 0.0005 & $<0.001$ & mda & $<0.78$ & mda & $<0.78$ & $\mathrm{DL}$ & $<56$ & mda & $<224$ & mda & $<0.012$ & mda \\
\hline Blank & 24.1 & 0.0028 & 0.0006 & 0.0406 & 0.0026 & $<4.44$ & mda & $<4.48$ & $\mathrm{DL}$ & $<46$ & mda & $<186$ & $\mathrm{mda}$ & $<0.016$ & mda \\
\hline Blank & 168 & 0.0022 & 0.0004 & $<0.001$ & mda & 0.24 & 0.08 & $<0.24$ & $\mathrm{DL}$ & $<60$ & mda & $<240$ & mda & $<0.010$ & mda \\
\hline
\end{tabular}




\subsection{REFERENCES}

${ }^{1}$ Hobbs, D. T., and Walker, D. D., Plutonium and Uranium Adsorption on Monosodium Titanate (U), WSRC-RP-92-93, Savannah River Site, Aiken, SC 29808 (August 13, 1992).

${ }^{2}$ Elder, H. H., Salt Blending Basis for Revision 12 of the HLW System Plan, HLW-SDT2001-00146, Rev. 0, Savannah River Site, Aiken, SC 29808 (April 26, 2001).

${ }^{3}$ Barnes, M. J., Hobbs, D. T., Peters, T. B., Stallings, M. E., and Fink, S. D. Task Technical and Quality Assurance Plan for Waste Characterization Support, WSRC-RP-2003-00403, Rev. 1, Savannah River Site, Aiken, SC 29808 (November 18, 2003).

${ }^{4}$ Barnes, M. J., Diprete, D. P., Hobbs, D. T., Peters, T. B., Stallings, M. E., and Fink, S. D., Effects of Ammonium Molybdophosphate (AMP) on Strontium, Actinides, and RCRA Metals in SRS Simulated Waste, WSRC-TR-2003-00572, Savannah River Site, Aiken, SC 29808 (January 27, 2004).

${ }^{5}$ F. F. Fondeur, D. T. Hobbs, M. J. Barnes and S. D. Fink, Sorption Modeling of Sr, Pu, $U$ and Np adsorption on Monosodium Titanate, WSRC-TR-2003-00180, Savannah River Site, Aiken, SC 29808 (May 2003).

Page 29 